\title{
2 Das Tridentinum und die Historia Ecclesiastica
}

De` libri, che si scrivono, già è finito il primo tomo, e se ben mi è richiesto di dargli in stampa, non mi par doverlo fare così presto per molte cause, quale hora non scrivo. [...] Dovete sapere, che tal negozio più preme a questi Padri di Casa, per honor commune della Casa, e Congregation nostra, che a qual si voglia altra persona, quai [...] nondimeno tutti d'un parere han giudicato, che si mette il mio nome solo, et in questo modo: Historia Ecclesiastica controversa R. P. Caesaris Baronii Sorani Presbyteri Collegi S. Oratorii etc. ${ }^{240}$

Die Entstehungsgeschichte der Annales Ecclesiastici des Oratorianerkardinals Cesare Baronio kann nicht mehr länger aus dem Blickwinkel der Auftraggeberschaft Filippo Neris erklärt werden. Damit ist auch die These von der Entstehung während Baronios frührer Jahre in Rom nicht mehr länger aufrechtzuerhalten. Baronio muss die Idee für seine Annales zwischen 1577 und 1579 gefasst haben, denn in diesem Zeitraum war er stark auf die Unterstützung des Kardinalpräfekten der Biblioteca Vaticana und Vorstehers der 1571 eingesetzten Indexkongregation, Guglielmo Sirleto, angewiesen. Ein Brief Baronios an den Vater Camillo, den der Oratorianer zwischen dem 14. August und dem 9. September 1578 verfasst haben muss, bezeugt diesen wichtigen Austausch mit Sirleto:

Io sto per gratia del Signore sano, se ben continuamente in fatighe de' soliti studii, impresa sopra le spalle mie, se non fusse l'aiuto del Cardinale Sirleto, qual ha cura di trovare, e provedermi di libri antichi scritti a mano della libraria Apostolica e sua. È fatiga da sudarci per molti altri anni; spero nella divina protettione, che Qui coepit in nobis opus bonum, perficiet solidabitque (Phil. 1, 6; Pt. 5, 10). Ho mostrato alcune risolutioni delle cose più difficili al detto Cardinale, al quale son piaciute estremamente, e l'ha laudate fra molti. ${ }^{241}$

Die Rolle, die Sirleto bei der Entstehung von Cesare Baronios Annales Ecclesiastici gespielt hat, blieb in der Forschung nicht ganz unberücksichtigt. Allerdings ist die Bedeutung Sirletos in Bezug auf den Einfluss der nachtridentinischen Kontroverstheologie auf die Kirchengeschichtsschreibung noch unerschlossen. Die Gestalt des Kardinalbibliothekars Sirleto war für Baronios Unternehmen, mit seinen Annales eine revidierte Kirchengeschichte vorzulegen, vor allem in Bezug auf Baronios Zugang zu der in der Biblioteca Vaticana aufbewahrten Handschriften- und Büchersammlung von zentraler Bedeutung. Derselbe Sirleto schlug dem Boncompagni-Papst Gregor XIII. vor, den Oratorianer Baronio ab 1580 in die Revisionsarbeiten der Kurie am Martyrologium Romanum einzubeziehen. Sirleto hatte den reichen Fundus an patristischen Texten in der Vaticana für seine eigenen Arbeiten sowohl am neuen Breviarum als auch am Missale Romanum verwendet. Der kenntnisreiche Kardinalbibliothekar stellte Baronio auch Übersetzungen griechischer Manuskripte bereit, die sowohl in Baronios Arbeiten am Martyrologium Romanum als auch in seine Annales einflossen.

240 BVR, Q 46, f. 47v-48r, Cesare an den Vater Camillo Baronio, Rom, 25. April 1579.

241 BVR, Q 46, f. 47r-v; Calenzio, Vita, S. 149; Laemmer, De Caesaris Baronii, S. 46-47.

Ә Open Access. (C) 2022 Filip Malesevic, publiziert von De Gruyter. (c) BY-NC-ND Dieses Werk ist lizenziert unter einer Creative Commons Namensnennung - Nicht-kommerziell - Keine Bearbeitung 4.0 International Lizenz. https://doi.org/10.1515/9783110741117-003 
Die Biblioteca Vallicelliana bewahrt die aus der Vaticana stammende Transkription und Übersetzung des Menologium Graecorum auf, die Sirleto Baronio schenkte. ${ }^{242}$ Dieser fruchtbare Austausch zwischen Baronio und dem Vorsteher der Indexkongregation beschränkte sich nicht nur auf Sirletos philologischen Umgang mit den Handschriften aus der Vaticana. Sirletos Wirkung innerhalb sowie ausserhalb einzelner Arbeitsgremien der Kurie wurde bereits unmittelbar nach dem Abschluss des Tridentinums spürbar, als sich die Problematik offenbarte, wie die konziliaren Dekrete ab 1564 überhaupt in den päpstlich-kurialen Herrschaftsapparat $\mathrm{zu}$ integrieren und in ein ekklesiologisches Verständnis der Romana Ecclesia umzusetzen waren. Die Versuche, eine umfassende Kirchengeschichte zu verfassen, traten während der zweiten Hälfte des Cinquecento nicht bloss als eine Randerscheinung der Implementierung dieser Dekrete auf. Aus Guglielmo Sirletos Sicht war eine Kirchengeschichte aufs Engste mit der Reform liturgischer Bücher verbunden, die gemeinsam einen Katalog „Heiliger Bücher“ ausmachten. Diese Zusammenstellung von Büchern, die in einer spezifischen Tradition gegenüber der Heiligen Schrift und der patristischen Literatur stehen sollte, wurde bereits während des Tridentinums als eine eigene, antithetische Kategorie gegenüber dem Index librorum prohibitorum aufgefasst.

Mit der Drucklegung des ersten Bandes der Ecclesiastica Historia im Jahr 1559 waren die Magdeburger Zenturiatoren unter der Leitung Matthias Flacius' bestrebt, die geschichtlichen Unwahrheiten in den Aufzeichnungen über das Papsttum und die römische Kurie anhand einer quellenkritischen Überprüfung des offiziellen römischen Narrativs der Kirchenentwicklung aufzudecken. Den Konzilsteilnehmern in Trient war bereits zum Zeitpunkt ihrer dritten und letzten Sitzungsperiode bewusst, dass es von Seiten der römischen Kurie an einer wirkungsvollen Antwort auf die Magdeburger Zenturien mangelte. Der Ermländer Erzbischof und Kardinal Stanislaus Hosius schlug dem Kardinal Otto Truchsess von Waldburg in seinem Brief vom 13. Februar 1561 vor, Guglielmo Sirleto solle diese Kirchengeschichte der Zenturiatoren lesen, „da diese mit zahlreichen kirchlichen Angelegenheiten (rerum eccle-

242 Das Menologium wurde dann später auch aus einer Kopie unter der Leitung des holländischen Jesuiten Andreas Schott in Canisius, Antiquae lectionis tomus II, Ingolstadt, Ex officina typographica Ederiana apud Andream Angermanium, 1602, S. 730-941, herausgegeben. Sirletos lateinische Abschrift findet sich in BVR, E 14. Das griechische Original findet sich in BAV, Vat. gr. 1613, und taucht in der zweiten Edition des Martyr. Rom. (1586), S. 10, n. $h$, auf: „[...] ut legimus pervetusto Menologio, quod asservatur Bibliotheca Ill., ac Reverendis. Guillielmi Sirleti Card. Amplis.: illudque ab ipso latinati donatum, propriaque manu maiori ex parte conscriptum velut ingentem thesaurum eius liberalitate possideo et (ut Hieronymi verbis utar de codice Pamphyli Martyris) 'tanto amplector, et servo gaudio, ut Croesi opes habere me credam'. Meminisse itaque lector debet, cum in his scriptis allegatur Menologium, me de eo semper intelligere“. In Ann. Ecc., X, S. 610-611 erwähnt Baronio wiederum das griechische Manuskript in seinen Einträgen zum Jahr $886 \mathrm{n}$. Chr. als volumen imaginibus magni pretii decoratum per dies singulos, singulosque Sanctos, de quibus mentio habetur in versibus. Zum Menologium vgl. Herklotz 1992, S. 46; Nicolò/Solinar 1988, S. LXXXV; Braesel 2009, S. 43. 
siasticarum) ausgestattet sei“. ${ }^{243}$ In diesem Zusammenhang muss auch eine bislang nur wenig berücksichtigte Abhandlung Sirletos gesehen werden. Es handelt sich dabei um die Abschrift eines am 7. Dezember 1570 verfassten Briefes des Jesuiten Petrus Canisius an denselben Kardinal Otto Truchsess von Waldburg. In Sirletos Abhandlung wird dieselbe Widerlegung der Magdeburger Zenturien vorgeschlagen, die auch Canisius wählte. Die Authentizität und damit Allgemeingültigkeit einer solchen Kirchengeschichte sollte das Resultat einer Wechselwirkung zwischen Papstbiographik und den Arbeiten an einem neuen Katechismus sein. ${ }^{244}$ Unmittelbar nach dem Erscheinen des ersten Bandes dieser protestantischen Kirchengeschichte nahm innerhalb eines Kreises von Kurienprälaten das Unternehmen zu deren Widerlegung seinen Anfang. Dieselben Prälaten, die an einer Entkräftigung der Magdeburger Zenturiatoren arbeiteten, sollten demzufolge auch für die Herausgabe eines neuen Catechismus Romanus zuständig sein. Erst mit dem Eintritt Cesare Baronios sowie des Jesuiten Roberto Bellarmino in den kurialen Arbeitskreis, der für die Widerlegung der Zenturien zuständig war, brachte diese Gelehrtenkommission im Winter 1576/77 ihre Tätigkeiten zum Abschluss. Anhand der kurialen Karriere Guglielmo Sirletos und seiner Anstrengungen sowohl für die Revisionen des Katechismus', die fast drei Jahre nach Abschluss des Konzils herausgegeben wurden, als auch für das Breviarum und Missale Romanum lässt sich ein bislang unbemerkt gebliebener Einfluss der Neubegründung des römischen Ritus auf die Festigung der doctrina cristiana feststellen. Im Prozess der Anfertigung einer gegen die Magdeburger Zenturiatoren gerichteten Kirchengeschichte begann die Formulierung einer designiert römischen Ritualsprache im Zusammenhang mit der Bedeutung der Liturgie überhandzunehmen. Im Folgenden soll daher gezeigt werden, wie Guglielmo Sirleto anlässlich der dritten Tridentiner Tagungsperiode mit seinen Arbeiten Einfluss auf das Feld der Kirchenhistoriographie nahm. Die Annales Ecclesiastici des Oratorianers Cesare Baronio stellen den Höhepunkt dieses Einflusses auf die Widerlegung der Magdeburger Zenturiatoren und ihrer Ecclesiastica Historia dar, wodurch sich eine neue Idee der Kirchengeschichtsschreibung innerhalb der Kurie zu bilden begann.

243 Braunsberger, Canisius Epistulae et acta, III, S. 29: ,[...] nam si quisquam aliua, est et ille varia quadam et multiplici rerum ecclesiasticarum cognitione praeditus, nec multos reperiri puto qui aeque multa ut ille legerint“. Vgl. Denzler 1964, S. 62.

244 BAV, Vat. lat. 6417, f. 167r: „Indignum facimus Ecc.am historiam tot modis a Sectarijs depravari. Abundat Roma viris doctis, et historiarum peritis, nagui profecto referret, ex his deligi aliquem ad conscribendas Pontificum vitas. Nunc Sectarij, quae nobunt, effingunt, nobis plane stertentibus. Iudicet R.ma D. I. quomodo succurri possit non modo praesenti sed etiam sequenti Ecclesiae, ita de Catechismis, et postillis quoque dixerim, salvo semper iudiciu sapientium. Sed opus plane videtur, ut ad huius aetatis ratione docendi modus accomodetur, praesertim quia nostri morbi nova expectant remedia cumque sit alia nunc ingeniorum, quam olim habitudo. Utinam Pont. Max. deligat idoneos viros scribenda illa, qua lucem et Maiestate adferant doctrinae Ecclesiasticae cum tantus etiam Doctorum proventus passim cernatur“. Vgl. zum Brief Canisius‘ dann Braunsberger, Canisius Epistulae et acta, III, S. 30-31. 


\subsection{Der usus Eucharistiae und die Kirchenhistoriographie}

Der erste Band der Magdeburger Zenturien wurde zu einem entscheidenden Zeitpunkt gedruckt, und zwar kurz nachdem Kardinal Giovanni Angelo Medici zum Nachfolger des verstorbenen Carafa-Papstes Paul IV. gewählt wurde. Die Widerlegung dieser Kirchengeschichte der Protestanten ist eng mit den Folgen sowohl des Augsburger Friedens und der Confessio Augustana als auch mit denjenigen des Wormser Kolloquiums von 1558 verbunden. Mögliche Antworten auf die Frage, wie eine Widerlegung dieser protestantischen Kirchengeschichtsschreibung anzustreben sei, wurden aber von Seiten der Kurie erst zwei Jahre nach dem Abschluss des Trienter Konzils mit der Einsetzung einer eigenständigen Kardinalskommission ernsthaft diskutiert. Die Forschung konnte bislang die grundsätzliche Frage, ob die Konzilsteilnehmer und allen voran die Mitglieder der Theologenkommission bereits zum Zeitpunkt der dritten Sitzung des Tridentinums an einer Widerlegung der Zenturiatoren und derer Ecclesiastica Historia gearbeitet haben, nicht beantworten. Der rege Briefwechsel, den der Kardinalsbischof von Augsburg, Otto Truchsess von Waldburg, mit dem Konzilslegaten Stanislaus Hosius zwischen 1560 und 1565 unterhielt, vermag die bislang unberücksichtigt gebliebene Bedeutung der Kirchengeschichte für das Konzil näher zu beleuchten. Zudem belegt dieser Briefwechsel, dass die Einbindung sowohl der Jesuiten - insbesondere des Paters Petrus Canisius - als auch des damaligen Kustoden der Biblioteca Vaticana und Apostolischen Protonotars Guglielmo Sirleto richtungsweisend für eine erfolgreiche Widerlegung gewesen sein muss. Ein am 7. Mai 1560 verfasster und an den Ermländer Erzbischof Hosius adressierter Brief des Kardinals Truchsess erklärt, in welcher Beziehungdie Arbeiten gegen die Zenturiatoren zur Widerlegung des Augsburger Bekenntnisses standen. Der Kardinal von Augsburg erwähnt, dass neben der von Papst Pius IV. gebildeten Kardinalskongregation zur Vorbereitung der dritten und letzten Konzilsperiode auch eine Kommission von zwölf Kardinälen eingesetzt wurde, die sich vor allem den rebus Germaniae widmen sollte. ${ }^{245}$ Die Mitglieder der Tridentiner Theologenkommission, zu denen die Kardinäle Hosius und Girolamo Seripando gehörten, widmeten sich in ihrer Widerlegung der protestantischen Lehre vom Gebrauch der Eucharistie ebenfalls dem Problem der Kirchengeschichtsschreibung. In den Augen der Konzilstheologen war nämlich die Verwaltung des allerheiligsten Sakraments aufs Engste mit der Darstellung einer historischen Entwicklung der Kirche verwoben.

245 Weber, Litteras, S. 17: „Sanctissimus dominus noster concilium habuit XII cardinalium, quo ego ab eo accersitus propter infirmitatem valetudinis iam aliquot dierum, lectica deferre necesse habui“. Die Gründung der Kardinalskongregation zur Vorbereitung des Konzils wird im avviso vom 4. Mai 1560 bestätigt: in BAV, Urb. lat. 1039, f. 153r. Vgl. zudem auch Pastor 1891-1933, Bd. 9, S. 420, der ein Manuskript aus dem Archivio Graziani wiedergibt, das ebenfalls die Gründung eines solchen Consilium pro restituenda Germania festhält. Orella y Unzue meinte jedoch, dass diese Kommission ihre Arbeiten mit der Eröffnung der dritten Sitzungsperiode einstellte und damit aufhörte fortzubestehen: Orella y Unzue 1976, S. 116. 
Sowohl für den Augsburger Kardinal als auch für die Kurie wurde eine Widerlegung lutherischer Theologie im Augenblick der Papstwahl von 1559 umso dringlicher, denn derselbe Truchsess klagte den Papstkandidaten Giovanni Angelo Medici der Häresie an. Während eines Gesprächs zwischen dem Kardinal und dem zukünftigen Papst erwähnte der Kardinal Medici offenbar die Zugeständnisse, die er den Deutschen nach seiner erfolgreichen Wahl zum Papst gewähren wollte. Der neugewählte Papst beabsichtigte, den Deutschen sowohl die Priesterehe als auch die Empfängnis des Laienkelches zu gewähren. ${ }^{246}$ Der Streit um den Laienkelch, der erstmals im Augsburger Bekenntnis als Kennzeichen der wahren Kirche beschrieben wurde und wodurch die Vergabe unter den beiden Gestalten von Brot und Wein auch ihre dogmatische Bedeutung erhielt, sollte ein besonders scharfer Dorn im Auge der Kurienlegaten anlässlich der dritten Konzilsperiode werden. Der Entzug des Laienkelches, den die Confessio Augustana in ihrem zweiten Teil gleich als ersten und gewichtigsten Missstand festhielt, begründete eine Differenz zwischen Priestern und Laien. Diese Unterscheidung war aber gemäss protestantischer Theologen keineswegs „wider Gottes Gebot“ und auch nicht „wider den alten Canones“. ${ }^{247}$

Die Debatten der Konzilsteilnehmer über die Frage des Laienkelchs und der damit verbundenen Kontroverstheologie lassen sich aus den am 6. Juni 1562 verfassten fünf Artikeln über den „Gebrauch der Eucharistie“ (usus Eucharistiae), die den Legaten vorgestellt wurden, ableiten. Vier von diesen fünf Artikeln knüpften an die bereits am 3. Oktober 1551 vorgelegten canones an. In ihrem Inhalt hielten sie den Empfang der heiligen Kommunion unter beiden Gestalten als Notwendigkeit des Heils fest. ${ }^{248}$ Der Dominikaner und Bischof von Modena Egidio Foscarari berichtete detailliert über die Zusammensetzung der Theologenkongregation, welche die von

246 Truchsess hielt das Gespräch in zwei memoriali fest: in BAV, Urb. lat. 847, f. 167v-174r, wovon der Kardinal Ridolfo Pio da Carpi Gebrauch machte, um die Wahl Gian Angelo de' Medicis zum Papst aufhalten zu können. Vgl. Bonora 2010, S. 25; Constant 1923, S. 162-163; Caravale 2016, S. 147. Truchsess zog dann aber später diese Vorwürfe zurück, wie auch ein Brief vom 31. Oktober 1559 von Pietro Carnesecchi an Giulia Gonzaga mitteilt. Vgl. dazu Firpo/Marcatto 1998-2000, II/2, S. 727-729.

247 Zit. n. Dingel 2014, S. 61, 86. Zum Augsburger Bekenntnis und den ersten Anläufen zu einer confutatio vgl. LThK, I, 1226-1229, und Immenkötter 1980, S. 205-214; Napiórkowski 1980, S. 215-216; Oberman 1980, S. 217-231. Hinsichtlich der Abendmahlslehre im Augsburger Bekenntnis: Vajta 1980, S. 545-577. Die politische Bedeutung der Kelchfrage sowie der Priesterehe lässt sich aus den Folgen des Augsburger Interims für das Reich ableiten, indem es Konzessionen für „Rückkehrende” stellte. Der damalige Nuntius von Santa Croce, der Kardinal Marcello Cervini, hatte beispielsweise für Böhmen den Laienkelch bei Erfüllung gewisser Bedingungen zugestanden, deren Ratifikation aber durch den Tod Pauls III. scheiterte. Vgl. Constant 1923, S. 39-41; CT, II, S. 439; Jedin 1937, Bd. 2, S. 170; Pollet 1990, S. 391-393.

248 CT, VIII, S. 528. Daran übte die Deputation von Kardinälen, wie aus einem Brief Carlo Borromeos vom 30. Mai 1562 hervorgeht, die Kritik, dass diese nicht im „Stil” der bisherigen Konzilien formuliert wurden. Zum Brief Borromeos vgl. Šusta 1904-1914, II, S. 179. Zu den im Anschluss an die 1551 zurückgestellten canones vgl. CT, VII/1, S. 178; Jedin 1949-1975, Bd. 3, S. 280-281. 
den Teilnehmern gestellten Fragen beantworten sollte. Der frühere Maestro del Sacro Palazzo, der einen gewichtigen Anteil an der Herausgabe des Index Pauls IV. hatte, teilte die Mitglieder in vier Parteien ein: (1) in solche, die von Pius IV. selbst berufen wurden; (2) diejenigen, welche die Fürsten bestimmten; (3) in solche, die als Prokuratoren abwesender Bischöfe teilnahmen und (4) in diejenigen, die als theologische Berater von Legaten, Bischöfen und Ordensoberen am Konzil teilgenommen hatten. Letztere Gruppe bildete die grösste Fraktion innerhalb der Theologenkommission. ${ }^{249}$ Im Zusammenhang mit dem Gebrauch der Eucharistie lag das Hauptproblem in der Frage begründet, ob Christus selbst die Kommunion unter beiden Gestalten für alle Gläubigen angeordnet habe. Die Theologenkongregation konnte hierzu keine befriedigende Antwort liefern, obwohl der Kelch für das kirchliche Lehramt gemäss den im Neuen Testament überlieferten Berichten zum Abendmahl allein für die Apostel bestimmt war und die Laien vomGebrauch ausschloss. Gemäss der Stelle im Lukasevangelium sollen die Jünger in Emmaus nur die Brotgestalt (Lk 24, 30-32) empfangen haben. Das endgültige Argument, mit welchem der heilsspendende Charakter der Kommunion affirmiert wurde, lieferte Luis Villetta, der als Begleiter des Bischofs von Barcelona den Begriff der unitas ementiae beider Gestalten in der Kommunion prägte. Für Villetta repräsentierte die Kommunion - vielmehr noch als der Wein - die Vorstellung der Nahrung der Seele vollends. Ein weiteres, von den übrigen Konzilstheologen aber kaum aufgegriffenes Argument Villettas sprach die Problematik noch deutlicher an: Christus ordnete die Doppelkonsekration für das Messopfer an, wodurch das blutige Kreuzopfer des in das Blut Christi verwandelten Weins sichtbar wurde. Der Kelch wurde damit nur mit dem Messopfer und den in der Apostelnachfolge stehenden Priester verknüpft. Die Laien, welche das Sakrament empfingen, wurden in dieser Auslegung sodann vom Kelchempfang bewusst ausgeschlossen. ${ }^{250}$ Obwohl sich die Theologen darüber einig waren, dass unter jeder dieser beiden Gestalten der eine, ungeteilte und unverkürzte Leib Christi empfangen werde, blieb die Frage offen, ob der Empfang beider Gestalten mehr Gnade vermittle als der eine Empfang der Brotgestalt. Die konkrete Bedeutung dieser Frage wird im Zusammenhang mit den gegenüber Papst Pius IV. geäusserten Anklagen des Kardinals von Waldburg klar: Wenn man sie nämlich bejaht, ist die Forderung nach dem Laienkelch berechtigt. ${ }^{251}$

249 CT, VIII, S. 541. Als päpstliche Theologen bezeichnete Foscarari Salmerón, Solisius, Torres, Camillo Campeggio und den Dominikaner Pedro de Soto. Zur Statistik der Zahl an Theologen während der früheren Tagungsperioden vgl. insbes. Jedin 1949-1975, Bd., S. 54-55, 270, 345, sowie für die dritte Tagungsperiode $C T$, VIII, S. 542, 550.

250 CT, VIII, S. 585-597, hier 585, 587. Das Votum Villettas wurde dann später bei Gryphus in Padua gedruckt. Vgl. auch die gelegentlichen Hinweise auf das Messopfer in CT, VIII, S. 597, 599. Zu Villetta vgl. insbes. LThK, X, S. 791.

251 Für die entschiedenen Stimmen gegen den Laienkelch innerhalb der Theologenkongregation vgl. $C T$, VIII, S. 552-554, 562. Für ihre Auseinandersetzung darüber vgl. dann insbes. Jedin 1949-1975, Bd. 4/1, S. 161-162. 
Villettas Argumente verknüpften die Laienkelch-Problematik mit der Frage, wie mit dem Messopfer Christi umzugehen sei. Mit der Notwendigkeit der Heilsspende durch die Kommunion und deren Empfang wurde unmittelbar die Widerlegung der Confessio Augustana angesprochen. In einem Brief Guglielmo Sirletos an den Konzilslegaten Girolamo Seripando vom 5. Dezember 1562 stellt der spätere Kardinalsbibliothekar eine Beziehung zwischen der confutatio des Augsburger Bekenntnisses und der Theologie des Messopfers her:

Tra i libri di papa Marcello, bona memoria, vi è una confutatione de la Confessione luterana; il titulo è con queste parole: Confutatio Confessionis luteranorum per complures doctores quibus datum id negotii fuerat composita et Caesareae maiestati in comitiis Augusten. oblata. M'è parso far trascrivere quel che fu risposto da quelli dottori deputati sopra l'articulo de la Messa et mandarlo a S. V. Ill.ma; sarà contenta legerlo et di me pigli il bon animo et facci conto che sia uno di quelli li quali, per non poter più, offrivano peli di capre al tabernacolo. ${ }^{252}$

In seinen weiteren Briefen vom 24. und 27. Juni sowie in demjenigen vom 12. Juli 1562 äusserte sich Sirleto auch über die Vergabe der Communio sub utraque, wobei er den Laienkelch entschieden ablehnte. ${ }^{253}$ Sirleto legte sein Augenmerk auf den Gebrauch des Laienkelches im Zusammenhang mit der liturgischen Messfeier, die er im Einklang mit der Chrysostomos- und Basiliusliturgie im Kontext der Eucharistie auslegte. Dieselbe Ansicht vertrat auch der Jesuit und Konzilstheologe Petrus Canisius während der Tridentiner Debatten, der in seinem Votum vom 15. Juni 1562 ebenfalls Bezug auf die Lehre des Heiligen Chrysostomos nahm. Dadurch präzisierte der Jesuitenpater die Bedingungen, unter denen der Gebrauch eines Laienkelchs überhaupt gestattet war. ${ }^{254}$ Sowohl Sirleto als auch Canisius lehnten sich

252 BAV, Vat. lat. 6179, f. 87r. Sirleto bezieht sich hier auf ein zwischen Hosius und Seripando stattgefundenes Gespräch über das letzte Abendmahl, welches ihm Seripando am 17. August 1562 schriftlich mitteilte: BAV, Vat. lat. 6189, f. 112r.

253 BAV, Vat. lat. 6179, f. 31r-36v, 37r-40r \& 41r-42v. Sirleto empfiehlt allerdings die Gewährung des Kelches nur unter folgenden Bedingungen: „Filiis prodigis, qui in regione longinqua morantur et forsan divina preveniente gratia surgent et venient ad matrem suam [...] filiis quoque, de quibus dubitatur, ne ob hanc unam causam negationis calicis discedant a domo patris eorum in regionem longinquam“. Zit. n. Jedin 1937, S. 171-172.

254 Dies betraf vor allem den dritten an die Konzilstheologen verteilten Artikel, CT, VIII, S. 528: „An, si honestis et Christianae caritati consentaneis rationibus concedendus alicui vel nationi vel regno calicis usus videatur: sub aliquibus conditionibus concedendus sit, et quaenam sint illae“. Für Canisius’ Votum vgl. dann CT, VIII, S. 557-588, hier 558: „Ad tertium respondit: Haereticis non est concedendus calix, ne sanctum detur canibus. Sunt aliqui nutantes, qui circumdati sunt ab haereticis, sed alias catholici sunt; hoc tantum petunt, ut calice uti eis liceat; non videretur denegandus, cum alias in religione et officio retineri non possunt, quod valde considerandum proposuit. De Boemis autem, qui ob absentiam pastorum in varios errores inciderunt, proposuit considerandum, convenire ut concedatur, ut ad fidem in omnibus aliis revertantur. Cuperetque tradi explicationem huius sacramenti, et inter cetera, Io. 6 loqui de Eucharistia, quem ita intelligendum comprobavit, ut Chrysostomus docet, cum ibi Christus de pane, de manducatione et bibitione loquatur, cum, si de fide voluit intelligere, suffecisset dicere id explicite uno verbo“. 
bewusst an die überlieferten Texte der griechischen Kirchenväter zur Frage des usus Eucharistiae an, um die lutherisch-protestantische Theologie des Laienkelchs zu entkräften und zu zeigen, dass die Tridentiner Lehre von der Spende der Kommunion mit den Lehren der griechischen sowie der lateinischen Kirchenväter übereinstimmte. Matthias Flacius Illyricus sprach sich aber in seinem 1556 gedruckten Catalogus testium veritatis für den Laienkelch aus, womit er die Arbeiten der Magdeburger Zenturiatoren bereits vorwegnahm. ${ }^{255}$ Damit die Kurie also eine erfolgreiche Widerlegung der Zenturiatoren und ihrer Ecclesiastica Historia überhaupt bewerkstelligen konnte, mussten die Konzilstheologen in Trient zuerst unter Einbindung der patristischen Theologie eine einheitliche Lehre des sichtbaren Messopfers Christi vorlegen. Damit liess sich nicht nur der Primatsanspruch der römischen Kirche innerhalb der menschlichen Heilserlangung kirchenhistorisch verankern, sondern damit sollte auch die Vormacht der römischen Kirche bei der Verwaltung dieses Sakramentes bestätigt werden, wie es im zweiten Kapitel des Konzilsdekrets festgehalten wurde. ${ }^{256}$ Die mit dem Problem der Vergabe des Laienkelchs verbundene Frage, wie der Wesenswandel Christi in der Spende der Eucharistie sichtbar sei, nimmt einen zentralen Platz in der kirchenhistoriographischen Widerlegung der Zenturiatoren seitens der in Trient versammelten Konzilstheologen ein. Der Jesuitenpater Canisius stellte die theologischen Grundlagen dafür bereit. Während die beiden iberischen Theologen Forerius und Orantes behaupteten, dass die Spende unter beiden Gestalten bereits in der Amtszeit Papst Gregors III. (731-741) abgeschafft worden sei, meinte Canisius mit Berufung auf den Benediktinerabt Rudolf von St. Trond, dass die Zweifaltigkeit der Eucharistie bis zur Wende des 11. Jahrhunderts administriert worden sei. ${ }^{257}$

255 Flacius Illyricus, Catalogus, S. 6-7: „Post sub trecentesimum circiter Domini annum, coeperunt quidem paulatim errorum quorundam, qui iam in Papatu grassantur, semina in Ecclesia spargi: non tamen ea tanta ac tam perniciosa fuere usque ad 600 ferme Domini annum, ut non nostrae potius ea religio, quam Papisticae consenserit, eiusque formam retulerit. Qui illius aetatis scriptores seu patres diligenter legit, ut Hieronymum, Augustinum, Ambrosium, Hilarium, Chrysostomum, etc. facileanimadverit, eorum sententiam in plerisque articulis eum nostra doctrina congurere [...]“. Vgl. hierzu zuletzt Stewart 2015, S. 49-52. Zur Bedeutung der Basler Drucke verschiedener Chrysostomus-Editionen, die in der ersten Hälfte des 16. Jahrhunderts bei Froben und Amerbach herausgegeben wurden, vgl. Hartmann 2015, S. 221-244.

256 COD, S. 726-727, mit Berufung auf 1 Kor 4, 1. Die Problematik lag demnach in der kirchenhistoriographisch korrekten Rekonstruktion von Apg 16, 3 und Apg 21, 26. Darin wird diese Vollmacht der Sakramentsverwaltung dem Apostel Paulus zugeschrieben. Vgl. auch die Stelle im ersten Brief an die Korinther: 1 Kor 11, 34.

257 Für die Voten der beiden iberischen Theologen vgl. CT, VIII, S. 550, resp. 559. Zu Canisius vgl. CT, VIII, S. 616 sowie Braunsberger, Canisius Epistulae et acta, III, S. 744-749, hier 747-748: „[...] et ad Cor. XI. resp. Paulum referre tantum historiam institutionis hujus sacramenti, non autem aliquod dare praeceptum; et Gelasius et Innocentius statuerunt sub utraque communicandum, et Leo id etiam statuit propter Manichaeos, quod ritus contrarius mutavit, et conc. Constantiense; quae mutatio ab ecclesia fieri potest. Fuit in antiqua ecclesia mos communicandi sub utraque, et ut ipsimet sumerent, et domi etiam conservarent [...]“. Vgl. dann entsprechend auch Jedin 1949-1975, Bd. 4/1, S. 163. 
In ihrer dreizehnten Sitzung vom 11. Oktober 1551 hatten die Konzilsteilnehmer den Wesenswandel Christi in Brot und Wein in ihr Dekret über das Sakrament der Eucharistie aufgenommen. ${ }^{258}$ Die Theologenkommission der letzten Tagungsperiode sah sich dementsprechend mit der weiterführenden Problematik, wie die von der römischen Kirche abweichende Praxis der Griechen kirchenhistorisch nachvollzogen werden solle, konfrontiert. Anhand des Briefverkehrs zwischen Girolamo Seripando und Guglielmo Sirleto lässt sich der Einfluss des Apostolischen Protonotars auf diese letzte Sitzungsperiode des Tridentinums aufzeigen. Sirleto hatte insbesondere zur Patristik schon während seiner Tätigkeiten als Berater Marcello Cervinis ab dem Zeitpunkt der Konzilseröffnung essenzielle Vorarbeiten geleistet. ${ }^{259}$ Damit half Sirleto der Kurie, das patristische Schriftgut - und vor allem dasjenige der griechischen Kirchenväter - von den Lutheranern zurückzuerobern. Diese Wiederaufnahme der Patristik in die Konzilsarbeiten erwies sich nach den Debatten um den Empfang der heiligen Kommunion sowie um das Messopfer Christi auch bei der Redaktion und Drucklegung des neuen Catechismus Romanus als zentral. Sirleto gelang es nämlich, darzulegen, wie mit Hilfe dieses Schatzes der Kirchenväter gezielt eine Verteidigung gegenüber den Anfechtungen der Magdeburger Zenturiatoren aufgebaut werden konnte. Jedoch gibt dies noch keine Antwort auf die Frage, in welchem Verhältnis der neue römische Katechismus zur Kirchengeschichtsschreibung im Cinquecento stand. Die Geschwindigkeit, mit welcher die Zenturiatoren ihre Ecclesiastica Historia herausbrachten, zeigt auf, dass die Kurie der Widerlegung dieser Kirchengeschichte eine hohe Priorität zugeschrieben haben musste. Bereits drei Jahre nach der Drucklegung der ersten Centuria wurden der fünfte sowie der sechste Band herausgegeben. Canisius schildert die Geschwindigkeit dieser Verbreitung der Zenturien auf dem Büchermarkt in mehreren seiner Briefe an Stanislaus Hosius. ${ }^{260}$ Bislang wurde der Catechismus Romanus seitens der Forschung nur im Zusammenhang mit seiner Bedeutung für die Entwicklung der doctrina christiana unter-

258 COD, S. 695. Vgl. diesbez. die patristische Auslegung bei Ambrosius in PL, XVI, Sp. 458-464. 259 Bislang ist in der Forschung die Frage noch offen, inwieweit Sirleto während der ersten Sitzungsperioden des Tridentinums seinen Einfluss ausübte. Entscheidendes Material zur Beantwortung dieser zentralen Frage bildet die reiche Briefkorrespondenz zwischen Cervini und Sirleto in BAV, Vat. lat. 6177-6178, und BAV, Vat. lat. 6189. Daraus sind 126 ausgewählte Briefe in CT, X, S. 929-955 für die Zeitspanne vom 22. August 1545 bis zum 12. März 1547 von Buschbell ediert worden. Vgl. ferner hierzu dann Denzler 1964, S. 14-21; Mouren 2004, S. 454; Paschini 1945, S. 185-195; Giombi 2003, S. 147-160; Piacentini 2012, S. 138-142; Borromeo 2012, S. 253; Russo 1989, S. 299; De Leo 1989, S. 335-344.

260 Vgl. hier insbes. das Briefschreiben vom 9. Februar 1562 an Hosius in Braunsberger, Canisius Epistulae et acta, III, S. 372: „Utinam prodeat aliquis ex doctissimis episcopis et theologis, quorum ingens isthic est numerus, qui ex professo refellat pestilentissimum illud opus Magdeburgensium theologorum eccl. hist. nuper editum“. Vgl. dann auch das Schreiben vom 11. April 1562 über den fünften und sechsten erschienenen Band der Zenturiatoren in ibid., III, S. 408, 491. 
sucht. Im folgenden Abschnitt sollen daher die vielschichtigen Bezüge zwischen dem Catechismus und der römischen Liturgik erläutert werden.

\subsection{Vom Ordo Romanus XLIX zum De ritu sepeliendi}

Am Anfang der Revisionen des Catechismus Romanus stand die Ablehnung des fünften Artikels über den Gebrauch der Eucharistie durch die Konzilstheologen, welcher die Notwendigkeit der Kommunion für Kinder beschrieb. Aus ihrer Verneinung dieser Notwendigkeit ergab sich die unterschiedliche Praxis in Bezug auf die Verwaltung der Eucharistie innerhalb der griechischen und römisch-lateinischen Kirche. Das am 16. Juli 1562 verabschiedete Dekret legte schliesslich fest, dass die Kommunion für Kinder nicht notwendig sei:

\footnotetext{
Schliesslich lehrt die heilige Synode, dass Kinder, die ihren Verstand noch nicht gebrauchen können, durch keine Notwendigkeit zur sakramentalen Kommunion der Eucharistie verpflichtet sind, denn sie sind durch das Band der Taufe wiedergeboren und Christus eingegliedert worden und können in diesem Alter die bereits empfangene Gnade der Kinder Gottes nicht verlieren. Doch darf man deshalb die alte Zeit nicht verurteilen, wenn sie einst in bestimmten Gegenden diese Sitte pflegte. Wie nämlich die heiligen Väter für jene Zeit ohne Zweifel einen anerkennenswerten Grund für ihr Vorgehen hatten, so muss man ohne Widerspruch glauben, dass sie es gewiss nicht aus Gründen der Heilsnotwendigkeit getan haben. ${ }^{261}$
}

Guglielmo Sirleto sah sich in einer Ablehnung der Kommunion unter beiden Gestalten durch die Tatsache bekräftigt, dass diese Art der Verwaltung auch in liturgischen Texten der griechischen Kirche nicht abgelehnt wurde. Sirletos Briefschreiben an Seripando vom 24. Juni 1562 verdient an dieser Stelle besondere Aufmerksamkeit. Darin führt der spätere Kardinal alcuni luoghi d'historie auf, deren Beschreibung er im sechsten Buch der Historia Ecclesiastica des Eusebius auffand. Die Ortsbeschreibungen in Eusebius' Kirchengeschichte ergänzte er mit eigenen Texttranskriptionen der Werke des Heiligen Basilius. ${ }^{262}$ In jenem Kapitel seiner Historia Ecclesiastica berichtet der spätantike Kirchenhistoriker Eusebius vom Greisen Serapion anhand der Überlieferung des heiligen Dionysius v. Alexandrien. Nachdem Serapion erkrankt war, forderte er seinen Enkel auf, ihm einen Priester zu bestellen, damit dieser ihn noch vor seinem Tod von seinen Sünden erlösen könne. Der Darstellung Eusebius` zufolge habe Dionysius v. Alexandrien den Sündenerlass für Sterbende angeordnet, die um einen solchen baten. Als der Knabe aber keinen Priester finden konnte, übergab ihm

261 Zit. n. Wohlmuth 2010, Bd. 3, S. 727; COD, S. 727. Vgl. insbes. Canisius' Antwort in CT, VIII, S. 558, sowie die weiteren abwegigen Vermutungen über die Motive der Kleinkinderkommunion $a b$ abolendum ritum idololatrarum in CT, VIII, S. 617.

262 BAV, Vat. lat. 6179, f. 32, wo Sirleto die Stelle aus Eusebius“ Historia Ecclesiastica (VI.44) wiedergibt. Eine Abschrift des Briefes liegt in BAV, Barb. lat. 884, f. 39r-36v, vor. 
Dionysius selbst „ein Stückchen von der Eucharistie mit der Weisung, es anzufeuchten und es so dem Greise in den Mund zu träufeln“. ${ }^{263}$

Wie ist Sirletos bewusster Rekurs auf die in Eusebius` Kirchengeschichte enthaltene Erzählung vom Greisen Serapion in Bezug auf die Bestattungskultur im römischen Stadtraum nach dem Carafa-Pontifikat Pauls IV. einzuordnen? Damals besass die Arciconfraternita di Santa Maria dell'Orazione e Morte als einzige Bruderschaft das Recht, eigene Bestattungsrituale für ihre verstorbenen Mitglieder zu praktizieren. Die Begräbnisgewohnheiten dieser Bruderschaften beeinflussten Onofrio Panvinios Arbeiten zur Rekonstruktion altchristlicher Begräbnisriten. Panvinios Schriften gelten als erste Nachzeichnungen von Begräbnisritualen im nachtridentinischen Rom. Der Augustinermönch hielt diese in seinem 1568 in Köln gedruckten Traktat De ritu sebeliendi mortuos apud veteris Christianos fest. Bis heute bleibt umstritten, in welchem Jahr jene Bruderschaft gegründet wurde. Mit Sicherheit lassen sich aber ihre ersten Tätigkeiten in die Mitte des Cinquecento einordnen. ${ }^{264}$ Die im römischen Diözesanarchiv aufbewahrten Dokumente stellen einen zuverlässigen Ausgangspunkt dar, um die von der Bruderschaft praktizierten Begräbnisrituale und deren Einordnung in das Rom der 1560er Jahre darstellen zu können. ${ }^{265}$ Papst Pius IV. erhob diese Bruderschaft, deren Mitglieder sich seit dem 4. August 1551 in der Kirche von San Giovanni in Ayno versammelten, mit der Bulle Divina disponente clementia zur Erzbruderschaft. ${ }^{266}$

263 Eusebius, Historia Ecclesiastica, VI.44, S. 317-318. Später wird Baronio dieselbe Stelle direkt aus Eusebius' Kirchengeschichte übernehmen, in Ann. Ecc., II, S. 485. Für die griechischen Schriften, die Sirleto in Ergänzung von Seripando erwähnte, vgl. PG, XX, Sp. 654; ibid., XXXII, Sp. 483.

264 Die unklare Datierung resultiert aus der Diskrepanz zwischen den ersten edierten Statuten der Bruderschaft aus dem Jahr 1590 und den Beschreibungen Roms nach der Jahrhundertwende, wie sie vor allem Fanucci, Trattato, S. 272, Piazza, Euseuologio Romano, S. 401, und Morichini 1842, I, S. 153, die eine Gründung im Jahr 1551 vorschlagen, liefern. Einzig Querini 1892, S. 491, schlug eine spätere Datierung auf das Jahr 1573, die womöglich aus einer missverstandenen Lektüre von Armellini, Le chiese di Roma, II, S. 425, resultieren könnte. Vgl. anders die Statuti della Venerabile Arciconfraternita della Morte, et Oratione, c. 2, welche die Entstehung in das Jahr 1538 setzen. Vgl. auch das Dokument einer visita apostolica in der Kirche von San Giovanni in Ayno aus dem Jahr 1566 in ASV, Misc. Arm. VII, II, Visitationes diversarum ecclesiarum Urbis antiquae, f. 24 r.

265 ASVR, Arciconfraternita di S. Maria dell' Orazione e Morte, b. 16: Libro del Secretario, 1562-1570. Ein Blick auf die weiteren Bestände, die die Zeitspanne zwischen 1570 und 1580 betreffen, zeigt zudem, dass Camillo Fanucci am 23. August 1579 wegen der unregelmässig betriebenen Ausübung seiner Tätigkeiten casso, et raso aus der Bruderschaft verwiesen wurde: ASVR, Arciconfraternita, b. 17: Libro del Secretario, 1570-1580, f. 291v. Daher erstaunt es umso mehr, dass sich seine Datierung dermassen von der in den Statuten enthaltenen Gründung unterscheidet. Für eine Erklärung des Jahres 1538 als Gründungsjahr der Bruderschaft vgl. Tachhi Venturi 1922-1992, II/1, S. 162-167.

266 Bull. dipl. rom., VII, S. 86-90. Papst Julius III. hatte der Bruderschaft bereits im Jahr 1552 die Spende einer Plenarindulgenz für alle Gläubigen, die an der Prozession des Heiligen Sakramentes und im Anschluss an die Predigt der quarant'ore in ecclesia Sancte Chatharine de Senis teilnahmen, erlaubt. Eine Abschrift der Konzession dieser Indulgenz befindet sich in ASVR, Arciconfraternita, b. 10: Istanze, 1693-1898. Concessioni, 1600-1892, Indulgenze, 1552-1881, die womöglich von Kardi- 
Eine der wichtigsten Leistungen dieser römischen Bruderschaft war es, ihre Begräbnisrituale in den ekklesiologischen Aufbau der Opere di Misericordia einzufügen. Die Werke der Barmherzigkeit wurden dabei als Metapher für den Baum der Nächstenliebe (caritas) verstanden. Die Mitglieder der Bruderschaft ergänzten ihre revidierten Statuten 1590 um die Passage aus dem Buch Tobiae, in welcher Gott Tobit wegen seiner Beweinungs- und Bestattungspraxis segnet. Damit wurde die karitative Aufgabe der Arciconfraternita di Santa Maria dell'Orazione e Morte festgelegt: Sie sollte nämlich die rechtmässige Bestattung von Menschen aus der ärmeren Gesellschaftsschicht, die sich ein Begräbnis nicht leisten konnten, ermöglichen. ${ }^{267}$ Das Begräbnis selbst lässt sich aber nicht im Katalog der Werke der Barmherzigkeit, welcher im Matthäusevangelium (Mt 25, 31-46) überliefert wird, finden. Erst mit der griechischen Patristik und vornehmlich mit den Texten Cyprians wurde das Begräbnis in die Werke der Barmherzigkeit aufgenommen, und zwar wegen des oben zitierten Buchs aus dem Alten Testament. ${ }^{268} 1520$ hatte die Bruderschaft von San Girolamo della Carità bereits ein besonderes Bestattungsritual entwickelt und praktiziert. Die 1536 verfassten Statuten der Bruderschaft enthielten ein Kapitel, in dem dieser modus sepeliendi beschrieben wird:

Veggendosi da per tutto per le vie publiche della Città gli cadaveri de morti non senza molto horrore, et stomachagine di quegli, che passavano, e gli medesimi (cosa veramente dishonestissima) posti in vendita, e così certo, che non altrimente da ciascuno de villissimi sepelitori de corpi morti, fossero portati alla sepoltura. Per levar dunque via questa macchia de tempi sì

nal Bernardino Maffei verfasst wurde. Die Blätter befinden sich in aufgelöstem Zustand. Vgl. hierzu Catalogo delle indulgenze 1781, I, sowie Serra 2007, S. 80-81. Im Januar 1571 wechselte die Bruderschaft dann in die Kirche von Santa Caterina della Rota: ASVR, Arciconfraternita, b. 17, f. 17v, 22r.

267 Statuti della Venerabile Arciconfraternita della Morte, et Oratione, c. 83, mit dem Verweis auf Tb 12, 12-13. Zur Begräbniskultur seit dem Hochmittelalter und den damit für karitativ tätige Bruderschaften verbundenen Problemen vgl. Ariès 1980, S. 212; Paglia 1984, S. 197-198; Terpstra 1995, S. 68-82; Henderson 1988, S. 383-394; Zardin 1998, S. 239-252.

268 DSAM, Bd. 10, S. 1330. Die Statuten nennen daher das Jahr 1538 als Gründungszeitpunkt der Bruderschaft, da sie in besonderer Weise auf den damals vorzufindenden Umstand von nicht bestatteten Leichen, die auf den Strassen Roms lagen, antwortete. Statuti della Venerabile Arciconfraternita della Morte, et Oratione, c. 1: „Nell'Anno del Signore 1538, alcuni devoti Christiani vedendo, che molti poveri, li quali ò per la loro povertà, overo per la lontananza del luogo, dove morivano, il più delle volte non erano sepolti in luogo sacro, overo restavano senza sepoltura, et forse cibo di animali, mossi da zelo di carità, et pietà instituirono in Roma una Compagnia sotto il titolo della Morte, la quale per particolare istituto facesse quest'opera di misericordia tanto pia, et tanto grata dalla Divina Maestà di seppellire li poveri Morti“. Tatsächlich war im Rom der ersten Hälfte des Cinquecento kein solches Begräbnis für die Armen bekannt. Villapadierna 1968, S. 275. Für einen Vergleich mit dem Zustand von Bestattungen im frühneuzeitlichen Frankreich vgl. Ariès 1980, S. 64-67, 94-103. Bereits im 15. Jahrhundert praktiziert die Bruderschaft von San Giovanni Battista della Pietà dei Fiorentini anlässlich der Pest von 1448 das Begräbnis von Leichen von Personen, die keiner Bruderschaft angehörten. Dieser war aber in Frankreich bereits gängiger Brauch. Vgl. hierzu Paglia 1984, S. 199. 
disonesta [...] commandorono [...] che gli corpi di quegli, che da questa vita a qual modo si voglia partono, ne possono per lo disagio loro, essere sepolti con pompa funerale, debbiano per certi huomini obbligati alla Caritade, overo da condursi a ciò per la Compagnia essere portati alla sepoltura, precedente un Sacerdote co'l Sacratissimo Vessillo della Croce, et à spese, e cura della Compagnia, accesi li torchi, se gli defunti, overo abbandonati dall'aiuti de suoi, e de propinqui, overo dalle proprie facultadi non potessero Christianamente essere sepolti [...]. ${ }^{269}$

Allerdings praktizierte die Bruderschaft von San Girolamo della Carità dieses Bestattungsritual nur unregelmässig. Zudem übte die Bruderschaft dieses Ritual nicht gemäss eines liturgischen officium aus. Die Statuten vermerkten nämlich, dass die Bruderschaft die Bestattungen nur a qual modo si voglia zu praktizieren habe. Aus diesem Grund setzte Pius IV. mit seiner 1560 erlassenen Bulle eine neue karitative Bruderschaft ein, die sich spezifisch der ordentlichen Bestattung von Leichen widmen sollte. Darüber hinaus wurde dieser Bruderschaft auch erlaubt, während der Bestattungsrituale Sakramente durch ihre Kapläne zu verwalten. Die Sakramentsverwaltung der Arciconfraternita della Morte e Orazione war vor allem auf die angemessene Verehrung der Heiligen Eucharistie ausgerichtet. Die Mitglieder der Bruderschaft liessen dafür innerhalb ihres Kirchenraumes von San Giovanni in Ayno eine eigene, der Eucharistie gewidmete Sakramentskapelle errichten. ${ }^{270}$

Diese Sakramentskapelle diente dann auch als eigentliche Begräbnis- und $\mathrm{Ru}$ hestätte zur Bestattung verstorbener Mitglieder der Erzbruderschaft. Solche Begräbnisse, welche die Bruderschaft in ihren Statuen als fatti rimarchevoli bezeichnete, sorgten zugleich für viel Aufmerksamkeit innerhalb der römischen Stadtgesellschaft. Denn anlässlich solcher Begräbnisfeiern wurden Leichen, die ursprünglich ausserhalb der Stadtmauern Roms begraben wurden, von den Mitgliedern der Bruderschaft exhumiert und in den Kirchenraum der Confraternita überführt, wo sie neu bestattet wurden. ${ }^{271}$ Die Statuten der Bruderschaft enthielten auch Bestimmungen, in denen die Totenmesse reguliert wurde. Zusammen mit ihren Prozessionen

269 Statuti della Compagnia della Charità di Roma, c. 13v-14r. Zur Begräbnispraxis der Bruderschaft vgl. insbes. Carlino 1984, S. 298-299.

270 Bull. dipl. rom., VII, S. 87: „Et insuper confraternitatem ipsam ad aliam ecclesiam seu locum ipsius Urbis sibi benevisum transferre, et inibi, si ecclesia non extet, ecclesiam unam cum suis oratoriis et mansionibus; si vero ecclesia inibi reperiatur, de illius pro tempore rectoris consensu, unam cappellam seu oratorium, in qua vel quo sacratissimi Corporis Christi Sacramentum reconditum esse debeat, et ad eius altare cappellanum, ad id per eosdem guardianos et officiales ad eorum nutum eligendum et amovendum, prout hactenus habuerunt, per quem missae et alia divina officia celebrari et ipsis confratribus Eucharistiae et alia sacramenta ecclesiastica ministrari possint, habere et retinere ac construi facere“. Die Einrichtung einer solchen Kapelle ging zurück auf die Cappella della Concezione in San Lorenzo in Damaso, welche die Bruderschaft seit 1551 für ihre Zusammenkünfte und die Verehrung des Heiligen Sakramentes der Eucharistie nutzte. Vgl. Statuti della Venerabile Arciconfraternità della Morte, et Oratione, S. 1-2; Bovio, La pietà trionfante, S. 142. 271 ASVR, Arciconfraternità Orazione e Morte, b. 6, Notizie Storiche, fasc. Fatti rimarchevoli accaduti alla Ven. Arciconfraternita della Morte nell' associar de' cadaveri. Ihre Datierungen verweisen aller- 
leistete die Bruderschaft mit ihren rituellen Anordnungen einen essenziellen Beitrag zur Herausbildung einer „Theatralik des Todes“, wie sie dann später im Barockzeremoniell noch stärker entfaltet wurde:

Condotto, che haveranno il morto in Chiesa li nostri Fratelli se gli arrecheranno d'intorno pregando Dio per l'anima sua, et non vi essendo religiosi, che cantino l'Offitio, suppliranno essi medesimi con carità, et devozione. Finito, che sarà l'Offitio tutti in ginocchioni canteranno il Salmo Miserere, et De profundis con il Requiem aeternam, et il versetto A porta Inferi et c., con l'Oratione solita che dirà il nostro Cappellano, et poi seppelliranno il Morto. ${ }^{272}$

Sowohl die Statuten der Bruderschaft als auch der Text der Bulle Papst Pius' IV. vom 17. November 1560 führen auf, dass insbesondere solche Leichen, deren Bestattung nicht gemäss dem dafür entsprechenden Ritus erfolgte, zu betreuen waren. Diese Fürsorge gegenüber den unrechtmässig bestatetten Leichen schloss auch die dafür notwendige Sakramentsverwaltung der Eucharistie mit ein. Jedoch enthält die Bestimmung, wie der Begräbnisritus dieser Bruderschaft auszuführen sei, keine Hinweise auf die Verwaltung der Eucharistie. Daher können die Bestattungsrituale dieser Bruderschaft nicht als charakteristisch für einen spezifisch römischen usus Eucharistiae angesehen werden. Die Beschreibung einer solchen Sakramentsverwaltung der Eucharistie nach römischem Verständnis lässt sich erst im erwähnten Brief Guglielmo Sirletos an Seripando finden. Sirletos theologische Ausführungen zeigten deutlich die Unterschiede zwischen der Ost- und Westkirche in Bezug auf die Verwaltung der Eucharistie auf. Was aber noch bis zum Abschluss des Tridentinums fehlte, war ein kirchenhistoriographischer Nachweis des Vorrangs der römischen Verwaltungspraxis gegenüber derjenigen der Ostkirche. Erst mit Onofrio Panvinios 1568 gedrucktem Traktat De ritu sepeliendi war es möglich, diese kirchenhistoriographische Unterscheidung der rituellen Verwaltungspraxis der Sakramente auch katechetisch, also in Übereinstimmung mit der vom Tridentinum bestätigten doctrina christiana, weiter auszubauen und der römischen Sakramentsverwaltung einen Präzedenzstatus gegenüber dem griechischen Verständnis eines usus Eucharistiae einzuräumen.

Panvinios kurzer Traktat wurde bislang einzig im Zusammenhang mit der Frage, inwieweit Cesare Baronios eigene Aussagen über die frühen Märtyrergräber in seinen Annales Ecclesiastici mit Panvinios Befunden übereinstimmen, berücksichtigt. ${ }^{273}$ Panvinios Traktat wurde neben einer Interpretatio vocum ecclesiastica-

dings auf die zweite Hälfte des 17. Jahrhunderts. Für eine eingehende Untersuchung dieser Erzählungen vgl. Serra 2007, S. 93-94.

272 Statuti della Venerabile Arciconfraternità della Morte, et Oratione, S. 84. Wie stark die Theatralik der römischen sowie florentinischen Bruderschaften hinsichtlich ihrer Bestattungspraktiken auch Auswirkungen auf europäische Fürstenhöfe hatte, bleibt ein noch zu untersuchender Forschungsgegenstand. Für erste Ansätze vgl. Vovelle 2000, S. 288-293; Nizzo 2015, S. 19-46.

273 Oryshkevich 2009, S. 178-179; Ronchini 1872, S. 207-226; Ferrary 1996, S. $13-25$ für den Zusammenhang mit Panvinios antiquarischen Studien. Vgl. dann auch Perini 1899 sowie zuletzt DBI 2014, 
rum und seiner Abhandlung De stationibus Urbis Romae den bereits sechs Jahre zuvor in Venedig erschienenen und von ihm nochmals überarbeiteten Vitae Pontificum Romanorum Bartolomeo Platinas als Anhang beigefügt. Der Traktat ergänzte die ursprünglich Pius IV. gewidmeten Papstviten Panvinios, in deren Einleitung auch die Rede von der Wiedervereinigung des Tridentiner Konzils war. ${ }^{274}$ Panvinios De ritu sepeliendi ist somit im Kontext der Entstehungsgeschichte des Tridentiner Catechismus Romanus zu lesen. Panvinio unternahm in seiner Abhandlung zu den altchristlichen Begräbnisriten erstmals den Versuch einer kirchenhistoriographischen Rekonstruktion einer für Bestattungsrituale gedachten Sakramentsverwaltung. Die entscheidende Grundlage eines ordentlichen Bestattungsritus bildete für Panvinio, wie er im ersten Kapitel seines Traktates ausführt, das Tripel der sogenannten viaticum-Sakramente im Zusammenhang mit der Vergabe der Sterbekommunion. Panvinio betrachtete daher die Sakramente der Busse und der letzten Ölung in ihrem besonderen Verhältnis zum Sakrament der Eucharistie. Ähnlich wie Guglielmo Sirleto leitet Panvinio diese Beziehung der drei Sakramente zueinander aus der bereits erwähnten Stelle in Eusebius' Historia Ecclesiastica über den Greisen Serapion ab. Im Tridentiner Dekret vom 25. November 1551 hatten die Konzilsväter die beiden Sakramente der Busse und der letzten Ölung bereits bestätigt

Bd. 81, S. 36-39, für eine generelle Einbettung des Traktates in das Gesamtwerk Panvinios. Die handschriftliche Grundlage, welche dann 1567 zur Publikation in der kölnischen Druckerei von Mathernus Cholinus gegeben wurde, bildet BAV, Vat. lat. 6786, f. 37r-58v.

274 Ferrary 1996, S. 12-15. Die beiden letztgenannten Traktate erwähnte Panvinio in seinen Vetusti aliquot rituales libri in BAV, Vat. lat. 4973. Diese Handschrift, die aus einer Arbeit Panvinios hinsichtlich der Bestände der vatikanischen Bibliothek 1564 entstand und die er Kardinal Alessandro Farnese widmete, ist eine überarbeitete Fassung der Vetusti Panvinios aus BAV, Vat. lat. 6112, f. 38r-257v. Panvinio überarbeitet diese auf der Grundlage einer Jacob Fugger gewidmeten Fassung, die sich heute in BSB, Clm 132, befindet. Eine weitere Fassung, die derjenigen aus der Biblioteca Vaticana mit der Widmung an Farnese selbst entspricht, befindet sich in BAM, H 142inf., f. 4r-222r. Für eine nähere Untersuchung dieser spezifisch auf die Verarbeitung der Ordines Romani gerichteten Handschrift Panvinios vgl. infra, Kap. 3.2. Auch wenn Panvinios De ritibus unter Pius V. publiziert wurden, darf es stets als ein in das Pontifikat Pius' IV. gehöriger Traktat gelten, da die Vorrede an den Ghislieri-Papst mit derjenigen für dessen Vorgänger übereinstimmt. Vgl. die Widmung an Pius IV. in Panvinio, Historia Vitae Pontificum (1562), o. S.: „[...] ut profanis sacras historias, sic harum scriptores longe illis praeferendos puto, tum propter excellentioris argumenti dignitatem, tum quod rari semper fuerint homines qui sibi in hoc scribendi genere laborandum duxerint. Nec ideo dico, quasi improbem illorum studia, qui rebus Romanis, Graecis et barbaris tradendis exornandisque se totos dederunt, sed quod antiquitatem Christianam, qua nihil antiquis nobis esse debet, negligant, et valde miror, et plurimum doleo. [...] post profana quaeque multis commentariss a me explicata ad res ecclesiasticas conscribendas maiorumque nostrorum memoriam renovandam animum converti. Accessit summorum virorum auctoritas et dignitas, a quibus, cum de Romanorum Pontificum et Cardinalium rebus gestis librum in manibus haberem, rogatus, ut appropinquante Oecumenici concilii tempore a beatitudine vestra pro ecclesiae pace et concordia indicti $[\ldots]$... 
und in Berufung auf die Stelle im Jakobus- und Markusevangelium als ,apostolische Überlieferung“ festgehalten (Jak 5, 14-15 und Mk 6, 13). ${ }^{275}$

Die entscheidende Neuauslegung der beiden Sakramente in Panvinios De ritu sepeliendi bezieht sich aber auf die kirchenhistoriographischen Nachweise bezüglich der Frage, wie das Sakrament der Eucharistie in diesem Sakramentenpaar seine Gnadenwirkung entfaltet. Ausgehend von der Begräbnisrede des griechischen Kirchenvaters Gregor v. Nazianz, der in der vorliegenden Studie zu einem späteren Zeitpunkt auch für den Zusammenhang zwischen Baronios Annales Ecclesiastici und den Arbeiten Sirletos näher untersucht werden soll, erklärte Panvinio, wie ein griechisch-patristisch verstandener usus Eucharistiae in den ambrosianischen Ritus überführt wurde. ${ }^{276}$ Der ambrosianische Ritus war für ihn in der Rede des Ambrosius auf den Tod seines Bruders Satyrus repräsentiert. Aufgrund von Panvinios Erläuterung zur 18. Rede des heiligen Gregor v. Nazianz ist festzustellen, dass er mit der Wortwendung pro more Eucharistiae zeigen wollte, wie der in den Ordines Romani enthaltene Ordo qualiter agatur in obsequium defunctorum erweitert wurde. Panvinio legte daher sein Augenmerk vor allem auf die griechisch-patristischen Ursprünge der häuslichen Eucharistiefeier, die ab dem 2. Jahrhundert vermehrt an die Stelle des Brauchs des Totenmahls getreten war. Panvinios De ritu sepeliendi steht an einer wichtigen Stelle in der Entwicklung der Sakramentsverwaltung für die Sterbe- und Begräbnisliturgie, da mit Hilfe dieses Traktats eine Kontinuität der seit dem Mittelalter gebräuchlichen Sakramentsverwaltung bis hin zu ihrer liturgischen Festlegung in dem 1614 gedruckten Rituale Romanum behauptet werden konnte. Jedoch konnte damit das Sakrament der Letzten Ölung im Zusammenhang mit der eucharistischen Wegzehrung noch nicht als Krankensalbung ausgelegt werden. Die sakramentale Wirkung der extrema unctio stellt ein „Gebet des Glaubens, der dem Kranken zum Heil wird“ (Jak 5, 15), dar. Das

275 COD, S. 710: „Institutam est autem sacra haec unctio infirmorum tanqua vere et proprie sacramentum novi testamenti a Christo domino nostro, apud Marcum quidem insinuatum, per Iacobum autem apostolum ac Domini fratrem fidelibus commendatum ac promulgatum. [...] Quibus verbis, ut ex apostolica traditione per manus accepta ecclesia didicit, docet materiam, formam, proprium ministrum accepta ecclesia didicit, docet materiam, formam, proprium ministrum et effectum huius salutaris sacramenti“. Vgl. auch O'Malley 2013, S 152; Jedin 1949-1975, Bd. 2, S. 321-323. Die vom Dekret aufgenommenen Bibelstellen befinden sich in Mk 6, 13 und Jak 5, 14-15. Während die Krankenheilung bei Markus nur als Zeugnis ihrer Sendung dient, gilt sie bei Jakob in ihrer Form als Salbung als äusseres und damit auch sichtbares Zeichen, mit welchem die göttliche Gnade verbunden ist.

276 Panvinio, De ritu sepeliendi, in BAV, Vat. lat. 6786, f. 38r-v: „Refert Gregorius Nazianzenus in oratione in funere patris, patreum suum sacerdotem ardentissima \& diuturna febri exhaustum, ab ancilla aliquando sinaxis tempore deductum manu in conventum ecclesiasticum, in quo pro more Eucharistiam, sed paucissimis, \& quibus tum per morbum potuit verbis consecratam, aliis \& distribuerit [...] Hoc vero de fratre suo Satyro Ambrosius commemorat in oratione in funere eiusdem: Priusquam (inquit) perfectionibus esset initiatus mysteriis, in naufragio constitutus [...]“. 
Sakrament der Letzten Ölung bildet damit stets eine Einheit mit der Busse und der Eucharistie. ${ }^{277}$ Dem Augustinermönch Onofrio Panvinio gelang es erstmals, diese Einheit aus den mittelalterlichen Ordines Romani und aus kirchenhistoriographischen Quellenbelegen für seine Historia Ecclesiastica zu rekonstruieren. Panvinios De ritu sepeliendi zog deshalb weitreichende Wirkungen für die Entstehung einer kurialen Kirchenhistoriographie nach sich, da mit der römischen Begräbnisliturgie eine Nachfrage nach einem noch genaueren Abgleich zwischen Katechese und dottrina cristiana entstand. Die Leistung einer von der Kurie anerkannten Kirchengeschichte lag darin, dass mit dieser eine Antwort auf die entscheidende Frage, wie der römische Catechismus mit der christlichen Lehre zu vereinbaren sei, gefunden werden konnte.

\subsection{Die Kirchenhistoriographie der doctrina christiana}

Während Onofrio Panvinio an der Zusammenstellung weiterer Ordines Romani arbeitete, die er sowohl Kardinal Farnese als auch Hans Jakob Fugger in Augsburg mit seinen Vetusti aliquot rituales libri vorlegte, berief Pius IV. eine Kommission ein, die sich der Herausgabe eines neuen Catechismus Romanus widmen sollte. $\mathrm{Zu}$ den Mitgliedern dieser Kommission gehörten Muzio Calini, Leonardo Marini und dem Bischof von Modena, Egidio Foscarari. Der spanische Dominikanertheologe Francisco Foreiro kam als viertes Mitglied hinzu. Foreiro war für die Abfassung des neuen Index zuständig und hielt sich am 6. Januar 1564 in Rom auf. ${ }^{278}$ Carlo Borro-

277 COD, S. 710: Et oratio fidei salvabit infirmum [...]. Das Rituale Romanum von 1614 sollte schliesslich die Sterbe- sowie Begräbnisliturgie auf mehrere Feiern aufteilen, die in unterschiedlichen Zusammenhängen entsprechend abgehandelt werden. Vgl. Bieritz 2004, S. 672-673; Kaczynski 1992, S. 241-343; idem 1984, S. 213; Grethlein/Ruddat 2003, S. 551-574. Zum sakramentalen Verständnis der Letzten Ölung gem. dem Tridentinum vgl. CR II 6,2-16; Bellinger 1987, S. 218-220, der aber das Sakrament als Krankensalbung bezeichnet, obwohl der Katechismus diesen deutlich als sacramentum extremam unctionis behandelt. Zur weiteren patristischen Tradition vor allem der lateinischen Kirchenväter vgl. PL, XVII, Sp. 1193-1194 (Ambrosius); ibid., LXXVIII, Sp. 235-236 (Gregor d. Gr.). Für weitere Abhandlungen der griechischen Kirchenväter vgl. PG, II, Sp. 551-552 (Dionysius); ibid., XLVIII, Sp. 641 (Chrysostomus). Zum Ordo Romanus XLIX vgl. die handschriftliche Überlieferung in BAV, Ott. lat. 312, f. 151v, und eine entsprechende Edition bei Andrieu 1931-1961, IV, S. 529-530, sowie die Untersuchungen bei Frank 1962, S. 360-415; Pagano 1980, S. 153; Franz 2001, S. $193-198$. 278 Hinsichtlich der Übereinstimmung der beiden Kommissionen - Index und Katechismus vgl. De Bujanda 1984-2016, Bd. 8, S. 97. Für die Zusammensetzung der Katechismuskommission vgl. die Briefschreiben in Pogiani, Epistolae et orationes III, S. 448-449. Pogiani war auch derjenige, dem die Aufgabe erteilt wurde, die verschiedenen Arbeiten der Kommissionsmitglieder stilistisch zu einer Einheit auszugestalten. Der Erzbischof von Mailand und Neffe Pius' IV., Carlo Borromeo, beaufsichtigte die Arbeiten der Kommission. Vgl. hierzu den Brief Borromeos an Foscarari vom 8. Januar 1564 aus der Biblioteca Universitaria di Bologna, Cod. 1621, I, f. 42r-v; Baluze/ Mansi, Miscellanea, III, S. 520-521; Pastor 1893-1933, Bd. 8, S. 308. 
meo drückte in seinem Schreiben vom 20. Januar 1565 an den Nuntius Zaccharia Delfino seine Zuversicht in Bezug auf die innerhalb von wenigen Tagen zu vollziehende Drucklegung des neuen Katechismus aus, obwohl die dafür notwendigen Arbeiten zu diesem Zeitpunkt aufgrund des Ablebens des Medici-Papstes gegen Ende desJahres immer noch nicht vollendet waren. Unmittelbar nach seiner Wahl zum Nachfolger Pius' IV. beauftragte der Ghislieri-Papst Pius V. Kardinal Guglielmo Sirleto damit, die bisherigen Arbeiten zum Katechismus zu überprüfen. Sirleto konzentrierte sich dabei auf die Auswertung von Zitaten, die er sowohl der Heiligen Schrift als auch den Schriften der Kirchenväter entnahm. ${ }^{279}$

Sirletos Überarbeitungen des Catechismus Romanus lassen sich sowohl mittels der in der Biblioteca Ambrosiana in Mailand aufbewahrten Briefkorrespondenz des Kardinals Borromeo als auch anhand Sirletos eigener Briefe, in denen er von seiner engen Zusammenarbeit mit Tommaso Manrique - dem damaligen Maestro del Sacro Palazzo - berichtet, rekonstruieren. Der spanische Dominikaner Manrique, der ein enger Mitarbeiter des Dominikaner-Prokurators Eustachio Locatelli war, zählte neben Sirleto und Marini ebenfalls zu den Mitgliedern der von Papst Pius V. neu eingesetzten Kommission, die an der Drucklegung des neuen Katechismus arbeitete. ${ }^{280}$ Aus der Zusammensetzung dieser neuen Kommission lässt sich ihre Arbeit am neuen Catechismus als eine Angleichung des kirchenhistorischen Umgangs mit der Buchzensur nach 1562 an einer dogmatisch-theologischen Begründung der doctrina christiana beschreiben, die deren einheitliche Auslegung zur Folge haben sollte. Der 1566 in der Druckerei Paolo Manuzios erschienene Catechismus sollte nicht nur als Vorbild für weitere Katechismen dienen, sondern war auch als allgemeingültiges Lehrbuch für Priester und deren Predigten gedacht. Den Zusammenhang zwischen Predigt und Katechese hatte der Jesuit

279 Pogiani, Epistolae et orationes, II, S. XXXXVIIII; LThK, IX, Sp. 794-795; Bellinger 1987, S. 31-38; Denzler 1964, S. 78-82; Catto 2003, S. 48-49 sowie Al Kalak 2017, S. 154-158. Das Briefschreiben Borromeos an Delfino vom 20. Januar 1565 befindet sich in NBD, IV, S. 276: „Fra pochi giorni si darà a la stampa il cathechismo, formato qui secondo l'ordine et la mente del concilio Tridentino, et stampato che sia, se ne manderanno a V. Sra molti volumi, et lei potrà dirlo a S. M.tà, acciò habbi tanto maggior contento, di non haver lascato stampare quel cathechismo heretico.”

280 In einem Brief vom 12. November 1566 an seinen Bruder Girolamo gab Sirleto nämlich selbst die Anweisung, dass alle Unterlagen dem Maestro del Sacro Palazzo gegen eine Empfangsbestätigung abzugeben seien, in BAV, Vat. lat. 6186, f. 29r-v: „Advertite che in quello inginocchiatorio quale tenevo innanci al letto et sotto il crucifixo in la parete di dentro, vi sonno molte charte scritte et il Catechismo in due volumi scritti a mano, dateli al R.do Padre maestro del sacro palacio et fatevi dar pilza dela ricevuta, perchè essendo l'originale del catechismo sarà bene che stiano in mano di sua paternità“. Vgl. auch Marinis Schreiben an Borromeo vom 28. Oktober 1566 in BAM, F 36 inf., f. 254r- $v$, sowie einen Brief Francesco Lombardis an Stanislaus Hosius vom 1. April desselben Jahres in Cyprianus, Tabularium, S. 414. Vgl. Al Kalak 2017, S. 154-156; Denzler 1964, S. 74, 80. Ein avviso vom 14. September 1566 in BAV, Urb. lat. 1040, f. $294 r$ berichtet ferner von der Erscheinung des neuen Katechismus in der römischen Druckerei des Paulus Manutius: „Dicono [...] che'l Catechismo è finito di stampare“. 
Antonio Possevino in seiner Bibliotheca selecta beschrieben. ${ }^{281}$ Der neue Catechsimus setzte sich somit aus vier Teilen zusammen: Am Anfang erfolgte im Teil De fide et symbolo fidei die Auslegung der Zwölfzahl der Apostel. Diesem schloss sich ein allgemeiner Teil über die Sakramente (De sacramentis in genere) an, der zu einem Decalogo divinisque legibus überführte. Der letzte Abschnitt, De oratione, eiusque in primis necessitate, zählte schliesslich die Regeln für die Predigt - insbesondere für das Pater noster - auf. Diese Aufteilung bestätigt einerseits, dass Guglielmo Sirleto nicht nur den Nachweis eines deutlichen Vorranges des römischen Sakramentsverständnisses und der Sakramentsverwaltung anstrebte. Andererseits weist die Aufteilung im Catechismus darauf hin, dass innerhalb der Kurie eine Debatte darüber entstand, inwiefern die römische Sakramentsverwaltung auch der in der mailändischambrosianischen Liturgie praktizierten vorzuziehen sei. Diese Streitfrage, welche Borromeos Metropolitandiözese Mailand stärker an die römisch-kuriale Verwaltungspraxis binden sollte, erreichte im Boncompagni-Pontifikat Gregors XIII. ihren Höhepunkt. Sie wird an anderer Stelle noch genauer erläutert werden. Vorerst ist es wichtig, auf die bislang unbeachteten Folgen, welche die im Catechismus Romanus formulierte Sakramentsverwaltung für die Historia Ecclesiastica gehabt hat, einzugehen.

Bislang ging die Forschung davon aus, dass die Arbeiten am Catechismus - insbesondere die Revisionen Sirletos - nur eine geringe Rolle bei der Herausgabe der beiden neuen liturgischen Bücher des Breviarum und Missale Romanum spielten. ${ }^{282}$ Guglielmo Sirletos Zusammenarbeit mit dem Maestro del Sacro Palazzo zeigt aber, dass der neue Katechismus weitreichende Folgen für das kirchenhistorische Verständnis darüber, wie der römische Ritus neu zu begründen sei, hatte. Der römische Ritus sollte also mit Hilfe der im Catechismus enthaltenen doctrina christiana auch kirchenhistoriographisch aufgefasst werden. Bereits ab 1562 begann Sirleto die römische Liturgie neu zu interpretieren. Zu diesem Zeitpunkt erlaubte ihm nämlich Tommaso Manrique, die im Index aufgeführten verbotenen Bücher zu lesen. Darunter befanden sich auch Bartolomé de Carranzas Kommentare zum Katechismus. ${ }^{283}$

281 Possevino, Bibliotheca Selecta, I, S. 218.

282 Al Kalak 2017, S. 133.

283 Zaccaria, Storia polemica, S. 305: „Cum R. Dominus Sirletus promotor fidei zelantissimus sit, et omnium haereticorum vehemens impugnator, quod fieri nequit, nisi ipsorum errores ex propriis fontibus hausisset; quare nos Fr. Thomas Manrique Sacrae Theologiae Professor, ac Sacri et Apostolici Palatii Magister supradicto Domino meo ac conprofessori facultatem concedimus omnium haereticorum libros penes se retinendi ac legendi, magnam inde utilitatem Ecclesiasticae doctrinae sperantes. Non abstantibus quibuscumque in contrarium“. Auch zit. in Denzler 1964, S. 74. Bartolomé Carranzas Comentarios sobre el Catecismo Christiano wurden unmittelbar nach ihrer Drucklegung in den spanischen Index librorum prohibitorum von 1559 aufgenommen. Zur Problematik von Carranzas Kommentaren zum Katechismus vgl. Fragnito 2005, S. 103-105; Catto 2003, ab indicem; Tellechea Idigoras 1988, S. 383 und Rodríguez/Lanzetti 1982, S. 111-116. Gregor XIII. verurteilte Carranzas Kommentare 1576 auf der Grundlage der Feststellungen der Indexkongregation vom 2. Juni 
Der neue Catechismus Romanus muss bereits am 2. September 1564 fertiggestellt worden sein. In einem Brief vom 11. Mai 1566 an Carlo Borromeo erklärt Leonardo Marini, inwieweit sich der neue Katechismus auf die Arbeiten am Breviarum und Missale Romanum beziehe. Marini berichtete ebenfalls, dass Guglielmo Sirletos Redaktion in Bezug auf den vorgelegten Catechismus - abgesehen von den sprachlichen und stilistischen Änderungen -nicht signifikant von der ursprünglichen Fassung abweiche. Sirleto muss daher schon nach dem Erstentwurf mit seinen Arbeiten am Katechismus begonnen haben. ${ }^{284}$ Sirletos Überarbeitungen des ersten Entwurfs zum neuen Catechismus stellen somit auch zentrale Vorarbeiten für seine Überarbeitungen des neuen Breviarium sowie des neuen Missale Romanum dar. Carlo Borromeo bestätigte dies in seinem Schreiben vom 20. Januar 1565 an Stanislaus Hosius. Darin teilte er dem Ermländer Bischof nämlich mit, dass der Katechismus zusammen mit dem Messbuch und dem Brevier gedruckt werden sollte. ${ }^{285}$ Demgemäss sind die Arbeiten am neuen Katechismus innerhalb desjenigen kurialen Prälatenkreises zu verorten, der sich nach 1560 auch der Widerlegung der Magdeburger Zenturiatoren zu widmen begann. Dadurch sollte das Projekt einer Kirchengeschichte der Neubegründung der doctrina christiana angepasst werden. Petrus Canisius legte als Theologe Kardinals Otto Truchsess von Waldburg selbst einen Katechismus vor, der als ein Vorläufer für die Arbeiten der unter Pius IV. einberufenen Kommission gelten kann. In seinem Schreiben an Hosius vom 1. März 1562 äusserte Canisius seinen Wunsch, dass diesem Katechismus „eine höhere Autorität zukommen sollte“. ${ }^{286}$ Mit seinen katechetischen Arbeiten wollte Canisius die sapientia Christiana mit einer Theologie der iustitia verbinden. Mit dieser Theologie der „Gerechtigkeit“ verwies Canisius ausschliesslich auf das Vermei-

1563, diese stellten eine sanam et orthodoxam doctrinam dar. Vgl. hierzu Tellechea Idigoras 1976, S. 219-231; Garcia Suarez 1970, S. 341-423 für einen Vergleich zwischen Carranzas Katechismus und demjenigen Pius' V.

284 BAM, F 37inf., f. 162r-163r. Vgl. auch das Briefschreiben Sirletos an Borromeo vom 3. Oktober 1565 in BAM, F 36inf., f. 456r: „Io non manco de l'opera mia sopra il Catechismo. Spero con gratia di Nostro Signor Dio d'haverlo espedito al fine di questo mese d'ottobre. Quando sarà veduta la fatica, credo non parerà lungo il tempo, che ho messo et metto in tutta via“.

285 CR, S. 1280-1281: „Catechismum habemus iam absolutum doctissimorumque hominum sapientia atque industria elaboratum, eum nunc perpoliunt ut, cum manus extrema accesserit, pius concinnius et perfectius divulgetur. Missalis quoque et Breviarii nova institutio propediem emittetur, qua in re fore arbitror, ut catholicorum omnium expectationi satisfiat“.

286 Cyprianus, Tabularium, S. 221-222: „Non ausim petere, quod impetratu forte sit difficile, gratum mihi tamen aut operi potius utile futurum esset, si auctoritas quaedam maior accederet, modo dignus tamen exiguus liber hac commendatione videatur. Iudicium esto penes illustrissimam celsitudinem tuam“. 1555 gab Canisius in Wien seine Summa doctrinae christianae heraus, woraus dann in Köln ein Parvus Catechismus Catholicorum 1559 gedruckt wurde. Zum Erfolg dieser katechetischen Arbeiten vgl. die Äusserungen Pedro de Ribadeneyras aus dem Jahr 1556 in MHSJ, Ribadeneira, I, S. 201: „[...] el catechismo de M.ro Pedro Canisio se ha estampado en buena forma en Louayna; y ha placido tanto universalmente a todos, que dentro de pocos días que se acabó de estampar, se despacharon todos los exemplares“. 
den von Sünden sowie auf die Ausübung guter Werke. Allerdings stellte er mit der sapientia Christiana ein Gerüst katechetischer Bestimmungen vor. Damit wollte der Jesuitenpater in Dillingen zeigen, wie der wahre Christ durch sein Leben in Glaube, Hoffnung und tätiger Liebe sowie durch die Anwendung der Sakramente zum ewigen Leben und damit auch zur Rechtfertigung seiner Sünden gelangen könne. ${ }^{287}$ Den wichtigsten Inhalt sowohl des kurialen als auch des canisischen Katechismus bildete die Lehrmeinung, dass sowohl die als symbolum als auch die als Sakrament verstandene Eucharistie die Wirklichkeit des Messopfers beinhalte. Diese Überzeugung verteidigten auch die Konzilsteilnehmer während der dritten Tagungsperiode, um die in Martin Luthers Formula Missae et Comunis 1523 formulierte Kritik der kirchlichen Messefeiern und den darin dargestellten Verfall der Messzelebration zu widerlegen. ${ }^{288}$

In dem drei Jahre nach Abschluss des Konzils gedruckten Catechismus Romanus wurde eine Einheit von Mess- und Kreuzesopfer betont, auch wenn dies das Tridentinum nicht ausdrücklich vorgeschrieben hatte. Das anlässlich der 22. Sitzung vom 17. September 1562 verabschiedete Dekret zum Messopfer erläuterte nämlich nur die beiden Stufen der Anbetung der Eucharistie als sacrificium im göttlichen Heilsplan. Wegen der Unvollkommenheit des levitischen Priestertums musste Jesus gemäss der Ordnung des Melchisedech als Priester erscheinen und all jene zur Vollendung führen, die geheiligt werden sollten. Dem Text des Konzilsdekrets zufolge hatte Christus das „blutige Opfer am Kreuz dargebracht“ und es für die Kirche als „sichtbares Opfer“ hinterlassen. ${ }^{289}$ Der neue Katechismus erklärte zusätzlich, dass diese Opferhandlung bei der Messefeier als ein Gleichnis zwischen Mess- und Kreuzesopfer dargestellt werde. Aus kirchenhistoriographischer Perspektive blieb bis zu

287 Bellinger 1987, S. 51-52; Catto 2003, S. 42-45; O’Malley 1993, S. 123-125; Al Kalak 2017, S. 141. Das Gliederungsprinzip geht auf Sir 1, 26 zurück.

288 WA, XI, S. 206: „Nam hoc negare possumus, missas et communionem panis et vinis ritum esse a Christo divinitu institutum, qui sub ipso Christo primum, Deinde sub apostolis, simplicissime atque piissime, absque ullis addimentis, observatus fuit. Sed succesu temporum tot humanis inventis auctus, ut praeter nomen ad nostra saecula nihil de missa et communione pervenit“. Vgl. Olson 1966, S. 85-87; Polman 1932, S. 95-98, sowie jüngst zum reformatorischen Diskurs über das Messopfer nach Luther - insbes. bei Helding - dann Bollbuck 2014, S. 68-69. Vgl. auch die Anschuldigungen der Reformatoren gegen das Messopfer in der Apologie der Confessio Augustana bei Dingel 2014, S. 138-404, sowie die neusten Forschungsdiskussionen in Wandel 2014, S. 39-114, 205-250.

289 COD, S. 732-733 sowie CT, VIII, S. 959-961, 751-755. Vgl. auch O’Malley 2013, S. 189-191 und Malesevic 2015, S. 24-26. Eine Synthese zum Tridentiner Messopferdekret in Bezug auf die Kontroverstheologie des Cinquecento findet sich bei Iserloh 1979, S. 372-381. Der Konzilslegat Seripando hatte vor dem 17. September 1562 einen Traktat De oblatione Christi in coena verfasst, in welchem er Argumente gegen die Auffassung, Christus habe sich bereits beim Abendmahl geopfert, vorlegte. Vgl. hierzu dann CT, XIII, S. 732-735 und Jedin 1937, Bd. 2, S. 186-192. Nichtsdestotrotz wurde dieser Opfercharakter in die Lehrkapitel aufgenommen, CT, VIII, S. 960. 
diesem Zeitpunkt somit die entscheidende Frage nach der Einheit dieser beiden Opfergestalten im Sakrament der Eucharistie noch offen. ${ }^{290}$ Daher beschränkte sich die Problematik bezüglich der Kirchengeschichte - solange keine Übereinstimmung beim Opfercharakter der Eucharistie gefunden werden konnte - nur auf die philologische Erarbeitung der mannigfaltigen Referenzen und Auslegungen der patristischen Schriften. ${ }^{291}$ Dies hatte Matthias Flacius im Vorfeld der Arbeit der Magdeburger Zenturien als deren wichtigster Mitarbeiter bereits 1550 in der Widerlegung der Predigten des Mainzer Weihbischofs Michael Helding vorgeführt. Flacius stützte seine theologischen Argumente gegen Heldings Messtheologie auf deren unkritischen Gebrauch des Pseudo-Dionysius. Hierzu verwendete er eine Edition zweier Kapitel des Historikers Polydor Vergil, der das Traditionszeugnis des Pseudo-Dionysius widerlegt hatte. Zudem fügte Flacius eine Beschreibung der Ungleichförmigkeit der Messe in Gallien und Rom durch Augustinus an, um auf die Entwicklungsstufen der Messe und ihrer Feierlichkeiten bis zu Gregor d. Gr. zu verweisen. ${ }^{292}$

Das Tridentiner Dekret zur Messefeier bildete damit einen geeigneten theologischen Rahmen, in welchen die ersten Versuche, die Magdeburger Zenturien zu widerlegen, einzuordnen sind. So ist beispielsweise die Entstehung des Textes Adversus novam Historiam ecclesiasticam des Juristen Konrad Braun, der ebenfalls in den Diensten des Kardinals und Erzbischofs von Augsburg stand, um 1561/62 in diesem Kontext zu deuten. Wegen Brauns Tod im Jahr 1563 wurde die Drucklegung dieser Kirchengeschichte zuerst auf Eis gelegt. 1565 entschloss sich der Jesuitenpater Canisius aber, diese Widerlegung samt einer Vita Brauns in Dillingen bei Sebald Mayer zu veröffentlichen. Braun warf in seinem Gutachten den Zenturiatoren vor, dass ihre Arbeit keine Geschichte der Kirche enthalten würde. Die Zenturiatoren würden mit ihrer Ecclesiastica Historia bloss eine Indoktrination darstellen, da sie durch eine einseitige Quellenauswahl zu Stande gekommen sei. Die theologischen Themen in der Kirchengeschichte - nämlich die Kapitel Glauben, Lehre, Sakramente, Zeremonien und kirchliche Verwaltung - seien auf der Grundlage der Kirchenväter zu schreiben. ${ }^{293}$ Braun schlug damit eine Vorgehensweise vor, die sich mit der Widerlegungsstrategie der Kurie zum Zeitpunkt der Einset-

290 Canisius hatte in seiner Eucharistiekatechese, im Abschnitt De sacrificio, einen Unterschied zwischen den beiden Opfern festgehalten: S. Petri Canisii catechismi, I, S. 30-36, 123-132; Bellinger 1987, S. 204.

291 Es genügt hier wiederum einen Brief Sirletos an Seripando vom 7. September 1562 aufzuführen, in welchem er neben patristischen Traktaten (PG, LXXX, Sp. 1772-1774 und ibid., LXXXIII/3, Sp. 3874 B) auch den Traktat De sacrificio Missae während der ersten Sitzungsperiode nennt: in BAV, Vat. 6179, f. 88r-92v, 91r: „Un dottore nominato magister Consilii, il quale credo che V. S. Ill.ma habbi conosciuto, ha raccolto molti luoghi in un trattato [...] in provare quod Dominus obtulerit in coena“.

292 Flacius, Zwey Capitel Polydori Virgilij, c. Bv-Ciijr. Hierzu dann die Diskussion bei Bollbuck 2014, S. 69-70; Feifel 1960, S. 160-166; Seidel 2012, S. 326-327, 341-346; Diener 1978, S. 84-85.

293 Braun, Adversus novam Historiam Ecclesiasticam, c. B 5v: „Immo contra historiae legem faciunt, ut historia sua doctrinam de fide, de sacramentis, de ceremoniis, de politica Ecclesiae adminis- 
zung einer Congregratio Germanica deckte. ${ }^{294}$ Allerdings legte Braun mit seinem Traktat keine stichhaltige historiographische Widerlegung der Zenturiatoren vor. Es ging dem Juristen in erster Linie darum, mit diesen ersten Entkräftigungsversuchen die Lügen der Zenturiatoren auf der Grundlage der patristischen sowie kirchenhistoriographischen Schriftüberlieferung aus dem frühen Christentum aufzudecken. ${ }^{295}$ Brauns Adversus novam Historiam Ecclesiasticam galt vorerst als polemische Widerlegung der Zenturien. Das Werk konnte nicht als endgültige Kirchengeschichte gelten, da Braun in seinem Werk die im neuen Catechismus Romanus festgelegte Einheit des Messund Kreuzopfers Christi im Eucharistie-Sakrament noch nicht miteinbeziehen konnte, da er bereits drei Jahre vor der Drucklegung des Catechismus verstarb. Dieses Gleichnis zwischen Kreuzes- und Messopfer hätte den ersten Versuchen gegen die Zenturiatoren womöglich das geeignete theologisch-dogmatische Instrumentarium für eine vollständige Widerlegung nach kurialen Massstäben geliefert. Der 1566 gedruckte $C a$ techismus Romanus stellte die wesentlichen Weichen für die kurialen Widerlegungsarbeiten, sodas schliesslich eine neue Richtung eingeschlagen werden konnte - hin zu einer vollständigen Kirchenge>schichte. Gemäss den Tridentiner Bestimmungen zur doctrina christiana konnte die Kurie eine Kirchengeschichte fordern, deren Narrativ sich aus der liturgisch-zeremoniellen Sichtbarkeit der Romana Ecclesia ableiten liess. Die von den Magdeburger Zenturiatoren begangenen abusi hätten damit katechetisch widerlegt werden können. Eine solche kirchenhistoriographische Erzählung, die dogmatisch mit der christlichen Lehre übereinstimmte, hatte jedoch erstmals Guglielmo Sirleto mit seinen Arbeiten an der Revision des neuen Breviarum Romanum vorgelegt.

tratione et similibus ad proprium historici munus non pertinentibus tradunt“. Vgl. Benz 2003, S. 27-28; Orella y Unzue 1976, S. 61-65. Zu Braun vgl. Bäumer 1988, S. 115-136; Rössner 1991.

294 Braunsberger, Canisius Epistulae et acta, V, S. 97 (Briefschreiben an Hosius, 17. September 1565) und ibid., V, S. 481-483 (Schreiben an Francisco Borgia, 31. Mai 1567). Auf Brauns Widerlegungsversuch verfasste Flacius ebenfalls eine Refutatio, die ein Jahr später in Basel bei Johannes Oporinus erschien. Vgl. Flacius, Refutatio invectivae Bruni, S. 12: „Passim tota Praefatio et ipsum scriptum audacissime vociferatur, nostram Historiam multa falso narrare, multa pervertere, addere, imminuere, malitiose detorquere. Quae cum sint longe gravissima crimina, praesertim in Historia, ubi potissimum sincera narrationis veritas requiritur [...] Sin firmas rationes ac evidentes demonstrationes requiris, quibus liquido adversarii probent nostram Historiam iure accusari et damnari et praesertim falsitatis redargui: nullas sane hic, ne minimas quidem, reperies“.

295 Dies hat der älteste und gleichnamige Sohn Wilhelm Eisengreins in seinem 1565 erschienen Catalogus auch folgendermassen festgehalten: „Ecclesiam Historiam conscribere, non ut novi quid adducerem, huius enim Eusebio Caesariensi, Rufino Aquileiensi, Euagrio, Nicephoro, Nauclero, Pontano, \& alijs, plenissimam congnitionem habemus, sed eo potissimum, ut improborum istorum blasphemias \& deliria, sanctorum Patrum scriptis devincerem, atque simul ostenderem, apud CHRISTI fideles semper fidei dogmata, easdem traditiones, a sua primaeva origine usque in hanc diem viguissem. DEUM semper Ecclesiam suam contra innumerabilies haereticorum novas adinventiones sollicitudine plus quam paterna in unitate fidei conservasse et protexisse“. Zit. n. Eisengrein, Catalogus, c. A 3r-v. Vgl. hierzu auch Benz 2003, S. 31. 


\subsection{Das Scheitern der ersten Kirchengeschichten}

Dass die römische Kurie von den ersten Versuchen, die Magdeburger Zenturien zu widerlegen, wusste, lässt sich anhand der Rolle des Kardinals Marcantonio da Mula und seines Briefwechsels mit dem Bischof von Ermland, Stanislaus Hosius, nachweisen. Da Mula wurde 1565 als Nachfolger Alfonso Carafas zum Kardinalbibliothekar der Vaticana berufen. Damit gelangte der frühere venezianische Botschafter in den Kreis gelehrter Kurienprälaten, die sich um Guglielmo Sirleto scharten. Der in der Druckerei Paolo Manuzios herausgegebene Index von 1564 nahm die Ecclesiastica Historia der Zenturiatoren als verbotenes Buch auf und ordnete es in die tertia et ultima classis ein. ${ }^{296}$ Am 5. Mai 1565 teilte Petrus Canisius Kardinal Hosius mit, dass Sirleto zusammen mit da Mula in der Vatikanischen Bibliothek an einer Neuordnung der dortigen Handschriften, die ein eigenständiges Archivium scripturarum ad romanos pontifices bilden sollten, arbeitete. ${ }^{297}$ In einem bislang noch nicht beachteten Briefschreiben an Hosius schildert Kardinal da Mula seine Strategie, wie das Werk der Zenturiatoren zu widerlegen sei. Das Antwortschreiben des Ermländer Bischofs vom 14. September nimmt diese kirchenhistoriographischen Gedanken da Mulas auf und versucht sie auch in Bezug auf die wichtigen theologischen Fragen zur Rechtfertigungsdebatte umzusetzen. ${ }^{298}$ Diese zentrale, aber seitens der Forschung bislang unberücksichtigt gebliebene Briefkorrespondenz zwischen da Mula und Hosius veranschaulicht, wie die Zenturiatoren in den Augen der Kurie betrachtet wurden, und zwar als eine von der Kirche „abgefallene“ (lapso) Gruppe. Da Mula und Hosius sowie im Übrigen auch Sirleto - waren der Überzeugung, dass die Kurie diese Kirchengeschichte der Protestanten noch in das ekklesiologische Geflecht der Romana Ecclesia zurückführen können würde. ${ }^{299}$ Die anonym verfasste Schrift Pro suffragijs sanctorum contra centurias Magdeburgensis, die den Konzilsvätern in Trient vorgelegt wurde,

296 gl. Reusch 1886, S. 246: „Tertia vero et ultima classis eos libros complecitur, qui sine scriptoris nomine exierunt in vulgus et iam doctrinam continent, quam romana Ecclesia tamquam Catholicae fidei aut morum integritati contrariam refutandam ac repellandam esse decernit“. Am 13. Januar 1560 wurde Da Mula zum ordentlichen Botschafter am päpstlichen Hof Pius’ IV. ernannt, 1561 folgte die Ernennung zum Bischof von Verona samt Kardinalat. Da Mula hatte vor seiner Ernennung zum Bibliothekarspräfekten 1564 Paolo Manuzio im Vorhaben der Einrichtung einer römisch-städtischen Druckerei stark unterstützt. Zu Da Mula vgl. DBI 1986, Bd. 32; Pastor 1893-1933, Bd. 7, ab indicem. Da Mula war auch der Vollstrecker von Seripandos Testament: Jedin 1937, Bd. 2, S. 87.

297 Baumgarten, Hispanica I, S. 138; Orella y Unzue 1976, S. 128.

298 Hosius, Opera omnia, I, S. 238-239. Aus diesem Antwortschreiben lässt sich das bislang nicht aufgefundene Briefschreiben Da Mulas als ein Fragment in BAV, Vat. lat. 3933, f. 34r-v bestimmen. 299 So im Briefschreiben Canisius' an Hosius vom 17. September 1565 in Braunsberger, Canisius Epistulae et acta, V, S. 97: „Ubi non sine voluptate cogito, quam recte ac sapienter scripserit pietas tua de successu calicis, de confutatione Centuriarum ac alijs quibusdam, quae his diebus mihi praelegit Illustriss: D. Amulius. Intellegit illa quoque Pont. Max. cui lngos precemur annos ad profligandas errorum tenebras, ad confirmandam Catholicae fidei veritatem, ad lapsos Ecclesiae restituendos“. 
schildert erstmals eine solche Korrektur protestantischer Kirchengeschichtsschreibung seitens der Kurie durch eine Herleitung über die Heilige Schrift hin zur lateinischen und griechischen Patristik. Es handelt sich bei diesem Schriftstück um ein Gutachten, das im Umkreis der Kardinäle Hosius, da Mula und Sirleto entstanden sein muss. Wie oben gezeigt wurde, haben die Konzilsväter in Trient die Bedeutung der Kirchenhistoriographie nur im Zusammenhang mit dem rechtmässigen usus Eucharistiae erläutert. Deshalb betont dieses anonyme Gutachten bewusst die Liturgie, wie sie der griechische Kirchenvater Basilius d. Gr. vertrat. Als Autor dieses Gutachtens wäre daher ein Mitarbeiter aus dem Umkreis Guglielmo Sirletos denkbar. ${ }^{300}$ Der Aspekt der ersten Widerlegungsversuche ging mit dem politischen Ziel der Kurie, nach Abschluss des Konzils einen Religionsfrieden mit den Lutheranern zu bewerkstelligen, einher. Bis zum Reichstag in Augsburg 1566 war eine solche Möglichkeit der einträchtigen Widerlegung protestantischer Kirchengeschichtsschreibung durch die Kurie noch vorstellbar. Nach mühseligem Ringen mit dem Kardinalskollegium beschloss Pius IV. im Konsistorium vom 8. März 1564 dennoch, den Laienkelch in Deutschland zu gewähren, worauf am 16. April Breven an die deutschen Bischöfe versandt wurden, welche die Zugeständnisse des Papstes festhielten. ${ }^{301}$ Mit dem neuen Catechismus Romanus, der nach der Papstwahl von 1566 gedruckt wurde, entschied sich die Kurie, beim Verlauf ihrer Arbeiten im Bereich der Kirchengeschichte die Tridentiner Beschlüsse zu befolgen. Das Ghislieri-Pontifikat Pius' V. hatte die bisherige Strategie für einen Religionsfrieden, der durch päpstliche Konzessionen an die Protestanten in Deutschland erlangt werden sollte, endgültig beendet. Dies hatte zur Folge, dass verschiedene theologische Fragen, wie die des Laienkelches oder der Priesterehe - die bisher noch als adiaphora bezeichnet wurden -, ab diesem Zeitpunkt als Häresien verurteilt wurden. ${ }^{302}$

300 BAV, Vat. lat. 3944, f. 164r-173v, hier 171v-172r. Die Handschrift besitzt starke Ähnlichkeiten mit einem Schreiber, der auch für Onofrio Panvinio bei seiner Zusammenstellung der Ordines Romani tätig gewesen sein muss. Dass es sich bei der Autorschaft dieses Gutachtens nicht um den Augustinermönchen Panvinio selber handeln kann, geht aus dem Konflikt zwischen Farnese und Da Mula im Pontifikat Pius' IV. hervor. Zu diesem Aspekt vgl. F. Malesevic, Reframing Roman Liturgy. A Critical Edition of Onofrio Panvinio's 'Vetusti aliquot rituales libri' (in Vorbereitung).

301 Zum Konsistorium vgl. den Bericht in BCR, Acta Concist. card. Gambarae, f. 277r-289v. Vgl. hierzu dann insbes. Pastor 1893-1933, Bd. 7, S. 374-382. Für das Breve an Julius Pflug, beispielsweise, vgl. Pogiani, Epistulae, III, S. 161.

302 Führend auf dem protestantischen Gebiet des Streites um die sog. Gnesiolutheraner war wiederum Matthias Flacius. Vgl. hierzu seine Traktate: Liber de veris et falsis adiaphoris, Magdeburg 1549 und Die vornehmsten adiaphoristischen Irrtümer, Jena 1558 in Dingel 2012, S. 112-353, resp. S. 778-837. Über die entscheidende Rolle Melanchtons in der Adiaphora-Kontroverse während des Augsburger Interims vgl. Manschreck 1957, S. 165-182. Zur Zeit ist eine Forschungsdebatte im Gange, welche der Frage nachgeht, inwieweit die heterodoxe Politik Cosimo I. de' Medicis ebenfalls stark vom konfessionellen Streit über die adiaphora beeinflusst gewesen sein könnte. Vgl. hierzu die Forschungsergebnisse in Brundin 2009, S. 57-76 sowie Murry 2014, S. 50-103, 133-242. 
Damit stellte die Kurie im Ghislieri-Pontifikat und während des Augsburger Religionsgesprächs von 1566 neue Rahmenbedingungen für den Umgang der Theologie mit den Protestanten auf. Die Drucklegung der beiden liturgischen Bücher des Breviarium und des Missale Romanum muss demgemäss im Zusammenhang mit diesem Umgang neu beurteilt werden. ${ }^{303}$ In welchem Verhältnis standen die Reformen des Breviarium Romanum zu denen des Missale? Wie vorhin bereits erläutert wurde, handelte es sich bei der Kardinalskommission, die zur Revision der beiden liturgischen Bücher einberufen wurde, um eine andere als diejenige, die für die Drucklegung des Catechismus Romanus zuständig war. Die Tätigkeit Guglielmo Sirletos sowie Egidio Foscararis und Leonardo Marinis in den Jahren unmittelbar nach der Papstwahl von 1566 zeigen dennoch, dass beide Kommissionen nicht nur gemeinsame Ziele verfolgten, sondern auch eng miteinander gearbeitet haben müssen. Diese fruchtbare Zusammenarbeit zwischen den beiden Kardinalskommissionen sollte es erlauben, die beiden liturgischen Büchern möglichst unter einheitlichen Vorschriften zu bearbeiten. Der Austausch zwischen den beiden Arbeitsgruppen lässt sich im Falle ausgewählter Kurienprälaten feststellen. Denn die bischöflichen Mitglieder der Revisionskommission - allen voran Foscarari und Muzio Calini kehrten noch vor der Drucklegung der beiden liturgischen Bücher in ihre Diözesen zurück, wo sie auf deren Erscheinen warteten. ${ }^{304}$ Im Folgenden soll deshalb der Einfluss, den Sirletos auf die Arbeitsweise einzelner Kommissionsmitglieder - vor allem auf diejenige Leonardo Marinis - ausübte, dargelegt werden.

303 Eine solche Wechselwirkung zwischen den politischen Rahmenbedingungen und den sich anbahnenden liturgischen Reformen durch das Tridentinum lässt sich auf die dritte Sitzungsperiode zurückführen. Und zwar sowohl in dem am 6. Juni 1562 der Tridentiner Konzilsleitung überreichten Reformlibell Kaiser Ferdinands I. durch die kaiserlichen Gesandten als auch in dem umfangreichen Schriftstück über die beobachteten Missbräuche bei der Messefeier, welche die Konzilsdeputation während der Messopferdebatte vom Spätsommer desselben Jahres am 8. August dem Konzilspräsidenten, Kardinal Ercole Gonzaga, vorlegte. Für die frühen Drucke zum Reformlibell vgl. CT, XIII, S. 661-685. Die Abusus, qui circa venerandum missae sacrificium evenire solent, partim a patribus deputatis animadversi finden sich abgedruckt in CT, VIII, S. 916-921.

$304 \mathrm{Zu}$ den beiden Kommissionen vgl. das Tridentiner Dekret aus der 25. Sitzung in COD, S. 797. Hierzu dann auch CT, IX, S. 1106 sowie die Briefe Borromeos in Mercati 1937-1941, Bd. 3, S. 371 und in Šusta 1909-1914, Bd. 4, S. 162. Das Konzil hatte schliesslich der Kurie sowie dem Apostolischen Stuhl diese Aufgabe der Redaktion und der neuen Herausgabe übertragen, wie Jedin 1966, Bd. 2, S. 524-525, dies bereits feststellte. Al Kalak 2017, S. 138-140, meinte jüngst anhand eines Briefschreibens Egidio Foscararis an Alfonso II d'Este vom 22. April 1564 zeigen zu können, dass die Revision der liturgischen Bücher vor derjenigen des Katechismus geschehen sei. Vgl. hierzu den Brief Muzio Calinis an Marco Loredano, Bischof von Nona, vom 25. Mai 1564 in CR, S. 1279: „La licenza è stata chiesta a Sua Beatitudine per nome nostro et, anchora che fin qui non l'habbiamo havuta risolutamente, nondimeno stiamo con buonissima spreanza di ottenerla domani: percioché olta l'Indice de' libri che è già stato publicato et il Breviario et il Messale, che si lascieranno riformati per doverli poi stampare al suo tempo, ancho del Catechismo si metterà tal ordine che con l'aiuto di Dio si potrà con maggior commodità condurre l'opera a suo fine, quando ciascun di noi si troverà alla sua chiesa“. 
Sowohl Hubert Jedin als auch Georg Denzler nahmen an, dass Sirleto vor seiner Kardinalsernennung kein ordentliches Mitglied der zur Revision der beiden liturgischen Bücher einberufenen Kardinalsdeputation gewesen sein konnte. Diese Vermutung bestätigt auch ein Briefschreiben Carlo Borromeos an Sirleto vom 17. Oktober 1565. Borromeo erinnert darin den Gelehrten Sirleto ausdrücklich daran, dass vor allem er für den grössten Teil dieser Arbeiten am neuen Brevier zuständig sei:

Essendo molto desiderato, et aspettato in queste parti di qua il Breviario riformato in Roma, et parendo, che tardi hormai troppo a comparire; m'è venuto in mente di raccomandara quest'opera a V.S.Ill.ma da cui dipende in buona parte; non perchè non sappia, ch'ella ci attenda con ogni diligenza, ma acciochè muova, et solliciti gli altri a siguitarla, si che se ne venga presto al fine. ${ }^{305}$

Die Revisionsarbeiten Sirletos am neuen Breviarium Romanum sind demzufolge im Zusammenhang mit seinem theologischen Verständnis des Opfercharakter der Messe zum Zeitpunkt der dritten Tridentiner Sitzungsperiode zu betrachten. Es war nämlich Sirleto, der den Konzilstheologen in Trient zu einem einheitlichen Verständnis von Kreuzes- und Messopfer verhalf. ${ }^{306}$ Sirletos grosser Arbeitsanteil an den Revisionen lässt sich aus seinen Verbesserungsvorschlägen zu der am 9. Juli 1568 erlassenen Bestätigungsbulle Pius` V. zum neu gedruckten Breviarium rekonstruieren. In diesen bezog sich Sirleto auf das 1535 erschienene Breviarium sanctae crucis des Kardinals Francisco de Quiñones. Sirleto bestand darauf, dass das neue Breviarium nicht von einem Brevier dal'anticho abweichen sollte. Mit aller Wahrscheinlichkeit bezog sich Sirleto mit diesem Verweis auf ein liturgisches Buch al'antico, das auf das Pontifikat Gregors VII. zurückgeht und welches im Ordo officiorum ecclesiae laternanensis des Priors Bernardo überliefert wurde. ${ }^{307}$ Sirletos Verbesserungsvorschläge für den Text der Papstbulle Quod a nobis zeigen, dass der Gelehrtenprälat das im Breviarium for-

305 BAV, Vat. lat. 6379, f. 5r. Noch im Dezember 1564 glaubte Borromeo, dass sowohl das neue Brevier als auch das neue Missale in Kürze erscheinen würden: Jedin 1939, S. 53-54; Denzler 1964, S. 86. Zur Aufnahme Sirletos in das Kardinalskollegium, die während des Konsistoriums vom 12. März 1565 geschah, vgl. ASV, Act. Cam. 10, f. 209r-v; ASV, Act. Vicecanc. 9, f. 4v; NDB, II/4: 323-324. Ein Gratulationsschreiben des Theatiners und Kardinals Bernardino Scotti vom 24. April 1565 liegt in BVR, I 17, f. 134r. Zwei Tage später, am 10. April desselben Jahres, gratulierte ihm der Kardinal und päpstliche Nuntius am Kaiserhof in Wien, Zaccaria Delfino: BAV, Vat. lat. 6181, f. 194r. Unklar bleibt bislang, ob Sirleto zu diesem Zeitpunkt schon die niederen Weihen empfangen hatte, wie dies Paschini 1935, S. 280, annahm. Am 18. April erhielt er jedenfalls die Weihe zum Subdiakon, worauf die Priesterweihe am 26. Oktober 1565 folgte: ASV, Act. Cam., 10, f. 226r.

306 Die bestätigt sowohl ein Brief Sirletos vom 23. Oktober 1563 in BAV, Vat. lat. 7021, f. 41r, als auch ein vom 4. November des gleichen Jahres erhaltenes Briefschreiben des Bischofs von Faenza, Battista Sighiselli, in BAV, Vat. lat. 6189, f. 198r. Vgl. Frutaz 1960, S. 190.

307 BAV, Vat. lat. 6171, f. 15r-18r. Vgl. Focke/Heinrichs 1939, S. 388-398; Klauser 1965, S. 117-152; Ditchfield 1995, S. 35. Vgl. auch Frutaz 1974, S. 100-102, der allerdings vorschlug, dass wenn die Kommission auf einen solchen Archetyp zurückgegriffen hätte, es einfacher gewesen wäre, das Brevier aus dem 1474 gedruckten Missale zu verwenden. Gemäss Frutaz hätte die Kommission somit 
mulierte Tagzeitengebet samt dessen entsprechenden lectiones auf eine ursprüngliche Form zurückzuführen beabsichtigte. Der zur Feier von Heiligentagen bestimmte Ritus war damit von drei Merkmalen geprägt: einer chronologischen Abfolge der darin enthaltenen lectiones, den Angaben über die Reliquien eines Heiligen und schliesslich den Hinweisen auf entsprechende Schriften. ${ }^{308}$ Diese Rückführung all'antico deutet auf die Neuerung des römischen Messritus hin, die Sirleto zusammen mit seinen Reformarbeiten am Breviarium verfolgt hatte. Carlo Borromeo hatte der Tridentiner Deputation zur Erneuerung des Messbuches ein Sakramentar Papst Gregors d. Gr. aus der Biblioteca Vaticana zur Verfügung gestellt, das Sirleto als damaliger Kustode der Vaticana gekannt haben muss. ${ }^{309}$

Guglielmo Sirleto führt damit die Messfeiern für die Tagzeitenliturgie auf die Vorschriften, die in Texten der Kirchenväter enthalten waren, zurück. Der spätere Bibliothekar der Vaticana hatte somit das Breviarium Romanum zu einer von den Ordines Romani unabhängigen Textgrundlage für den liturgischen Vollzug des römischen Ritus gemacht. Sirleto glich die Tagzeitenliturgie im Breviarium an die im Missale Romanum enthaltenen Vorschriften zur Messzelebration an, indem er sich auf das Sakramentar Gregors d. Gr. stützte. Das theologische Gleichnis zwischen Kreuzes- und Messopfer Christi wurde dadurch in die Tagzeitenliturgie überführt. Sirleto gab dem Breviarium dieselbe liturgische Bedeutung, die dem Missale Romanum zukam, indem er die patristische Schriftüberlieferung sowohl für die lectiones im Breviarium als auch für die rituellen Vorschriften zur Messefeier im Missale verwendete. Die liturgische Gleichrangigkeit zwischen Brevier und Messbuch, welche von einer sichtbaren Theologie der Gleichwertigkeit zwischen Kreuzes- und Messopfer Christi geleitet war, trat erstmals im Kurienzeremoniell für das jährlich stattfindende Fronleichnamsfest (Corpus Domini) von 1567 zutage. Von allen Festen im liturgischen Kalenderjahr ist es dieses, an welchem der Priester den Gläubigen den Wesenswandel des Leibes Christi am offenkundigsten darlegt. Die Transsubstantia-

nur vorgehabt, zum alten franziskanischen Kalender aus dem 13. Jahrhundert zurückzukehren. Vgl. diesbez. die Annotationen Sirletos zum Proprium sanctorum in BAV, Vat. lat. 6283, f. 51r-180r.

308 Ditchfield 1995, S. 37-42 mit Beispielen zu den im Breviarium enthaltenen lectiones für die Heiligenfeiern der heiligen Augustinus und Ambrosius. Vgl. auch Smedt 1876, S. 484-487 für eine Liste solcher Schriften, auf die im Brevier verwiesen wurde.

309 Vgl. das Briefschreiben Borromeos vom 20. Oktober 1563 in ASV, Conc. Trid. 48, f. 139r: „Havendo il S.or Car.le di loreno veduto in questa libraria vaticana un Messale antico che chiamano di san Gregorio; sua Sig.ria Ill.ma hà giudicato molto à proposito che si mandi costà, acciò sia visto da li Deputati à riformar il Messale moderno.” Zit. auch in Frutaz 1974, S. 86. Es handelte sich dabei um das in BAV, Vat. lat. 3806 erhaltene Sacramentarium Fuldense, welches ein Regensburger Mönch um das Jahr 1000 niederschrieb. Montaigne berichtete darüber auch in seinem Journal de voyage, S. 112. Hierzu dann auch die Problematik hinsichtlich des Verhältnisses zwischen öffentlichem und privatem Gedankengut in Montaigne bei Reiss 1983, S. 127-152. Der Deputation zur Reform des römischen Messritus lag auch ein 1558 in Venedig herausgegebenes Missale vor. Dieses ist nun ebenfalls in der Vaticana vorzufinden: BAV, Stamp.Arch.Cap.S.Pietro.438; BAV, Stamp.Barb.B.IX.23. 
tionslehre folgt in der fünften lectio auf eine Predigt des heiligen Thomas v. Aquin über die Eigenschaft des Eucharistie-Sakraments: dum invisibile visibiliter sumitur, sub aliena specie occultatum. ${ }^{310}$ Theologisch wird in diesem Wesenswandel aus der unsichtbaren Wirkung der Eucharistie gegenüber dem Gläubigen eine Sichtbarkeit erzeugt. Das Sakrament der Eucharistie sollte dem Gläubigen in ihrer Materie „wahrhaftig” (veriter) als Speise, deren Wirkung in der „Reinigung der Sünden” (purgantur peccata) liegt, sichtbar vorgeführt werden.

Die im Breviarium Romanum eingefügte Predigt führt das theologische Verständnis des Fronleichnamsfestes auf den heiligen Thomas v. Aquin zurück. Als ein dem Dominikanerorden zugehöriger Papst, der diesen Heiligen 1567 in den Kanon lateinischer Kirchenväter erhob, hatte Pius V. das Corpus Domini-Fest dem theologischen Verständnis Thomas v. Aquins folgend vom Kurienzeremoniells begleiten lassen. Dies geht sowohl aus den Einträgen im Tagebuch des Zeremonienmeisters Cornelio Firmano als auch aus dem päpstlichen motu proprio hervor. Es erstaunt nicht, dass der Entwurf für das päpstliche motu proprio durch Kardinal Alessandro Farnese verfasst wurde, hatte der Kardinal doch reges Interesse an der kurienzeremoniellen Ausgestaltung dieses liturgischen Hochfestes gezeigt. In seinem Stundenbuch, das der Miniaturmaler Giulio Clovio ausschmückte, findet sich eine detaillierte Darstellung der Fronleichnamsprozession, die mit den rituellen Vorgaben des Kurienzeremoniells übereinstimmt. ${ }^{311}$ Ein Eintrag im Tagebuch des englischen Pilgers Gregory Martin erlaubt es, sowohl den Prozessionsweg als auch den für das Zeremoniell eingesetzten apparato zu rekonstruieren:

About a fourtnight before they begin to sette up great long postes on both sides of the way from the Palace gate downe to the great Palace built by Cardinal Camegius and so cross over the way by a Churche belonging to the compagnie of the b. Sacrament to the Cardinal of Trent his house and up to S. Peter's church door. Over these postes through out is drawn a goodly canvas tentwise with a flat roofe to keepe of al matter of wether. The sifes are hanged round about with the best tapestrie, the Popes hangings without the Palace gat his hangings first

310 Brev. Rom. (MLCT, 3), S. 487 und dessen Einbettung innerhalb der Oktav prima quinta feria post octavam Pentecostes in ibid., S. 490-491. Die Textstelle führt ebenfalls aus, dass das Fest von Papst Urban IV. eingeführt wurde. Es ist bemerkenswert zu lesen, dass keine Referenz auf das legendäre Wunder bei der Messe von Bolsena, das anscheinend Urban IV. zur die Einführung dieses Festes veranlasst haben soll, zu finden ist. Vgl. hierzu die Untersuchungen bei Bertamini 1968, S. 29-58; Rubin 1992, S. 176; Walters/Corrigan/Ricketts 2006, S. 32-36.

311 Das päpstliche motu proprio befindet sich in BAV, Vat. lat. 12285, f. 42r-44r, das eine präzise Beschreibung des Prozessionszuges enthält, die ebenfalls in Frimanos Tagebuch in BAV, Vat. lat. 12283, f. 99v-102r auftaucht. Vgl. die neusten Untersuchungsergebnisse hinsichtlich der Dekoration des Farnese-Stundenbuches bei Doulkaridou-Ramantani 2017, S. 349-375; De Laurentiis 2014, S. 160-175; Calvillo 2008, S. 61-96 auch in Bezug auf das Towneley-Lektionar, welches als Messbuch der Cappella Sistina diente. Zu Firmanos Aufzeichnung der kurienzeremoniellen Feierlichkeiten zum Fronleichnamsfest vom 23. Juli 1566 vgl. das Tagebuch in BAV, Vat. lat. 12283, f. 98v-103r sowie die später angefertigte Abschrift in BAV, Chig.L.II.28, f. 27r-29r. Das Stundenbuch des Kardinals bedarf noch einer genaueren Untersuchung in Hinblick darauf, inwieweit Farnese damit seine eigenen Vorstellungen zur Ausgestaltung des Kurienzeremoniells zu vermitteln suchte. 
that is the cheefe Cardinal and so along by senioritie every Cardinals best tapestrie with their armes for distinction so that they furnish the whole compasse byside the goodly clothes that the citizens hang out of their upper windows and the garlands of greneleaves and flowers adorning the postes and the toppe spaces betwene every man from high to lowe by such variety of service casting as yt were clothes and boughes in the way that Christ is to passe. ${ }^{312}$

Die Corpus Domini-Feierlichkeiten nahmen im Verlauf des Cinquecento ein solches zeremonielles Ausmass an, dass die Liturgie dieser Feier zunehmend an die kurienzeremoniellen Vorschriften zur päpstlichen Inbesitznahme der Stadt nach der Krönung (possesso) angelehnt wurde. Die eigentliche Feier der Eucharistie als Andenken an den geopferten und gekreuzigten Körper Christi wurde damit allmählich zu Gunsten der sichtbaren Inbesitznahme Roms durch den Pontifex verdrängt. Daher war es für Sirleto umso dringender, die Bedeutung des Sakramentes während des Fronleichnamsfestes als einen Akt des Andenkens an das Kreuzes- und Messopfer Christi im neuen Breviarium entsprechend festzuhalten, und zwar durch den Bibelvers hoc facite in meam commemorationem. Im Zusammenhang mit dem Fronleichnamsfest ist Sirletos wichtigster Beitrag an den Überarbeitungen des neuen Breviarium in der Einsetzung der Predigt des Heiligen Chrysostomos zu erkennen. In dieser Predigt wird nämlich die angesprochene Heilswirklichkeit der Eucharistie als mysterium betont. ${ }^{313}$ Sirletos Rückgriffe auf die griechischen Kirchenväter spiegelten zugleich die von der Kurie gewählte Strategie, die Magdeburger Zenturien einerseits und die protestantische Geschichtsschreibung nach Luthers Wider das Papsttum zu Rom von 1545 andererseits $\mathrm{zu}$ widerlegen, wider: Die Kurie verstand die Kirchengeschichtsschreibung nicht mehr länger als philologische Überprüfung des überlieferten Schriftmaterials, sondern als das eigentliche Erbe patristischer Schriftüberlieferung. Die Kirchengeschichte sollte die bislang fehlende Verbindung zwischen der Heiligen Schrift und den daraus entnommenen und in den liturgischen Büchern festgehaltenen rituellen Vorschriften bilden. Mit der Drucklegung sowohl des neuen Breviarium als auch des überarbeiteten Missale Romanum wurde somit durch Sirletos Rückgriffe auf die Kirchenväter eine Kontinuität zur Heiligen Schrift geschaffen. Damit konnte in

312 Martin, Roma Sancta, S. 86-87; Ingersoll 1985, S. 151-155. Vgl. auch das avviso in BAV, Urb. lat. 1040, f. 298r-v, in welchem Pius V. topographisch-urbanistische Bestimmungen für den Borgo trifft. Die feierliche Papstmesse begleiteten die Kardinäle Morone, Farnese sowie Vitelli. Den assistierenden Priestern und Diakonen dienten die Kardinäle del Monte und Simoncelli. Firmano berichtet aber noch über einen zwischen den Kardinälen Farnese und Morone ausgebrochenen „Streit für die am Tag folgende Prozession”, die im Borgo stattfinden sollte. Dabei äusserte Farnese den Wunsch, dass die an der Prozession teilnehmenden Kammerdiener (cubicolarios participantis) den vornehmsten Platz innerhalb des Zuges einnehmen sollten, während sich Vitelli diesem Vorschlag entgegenstellte: BAV, Chig.L.II.28, f. 28v-29r Zum Kurienzeremoniell des Fronleichnamsfestes während der ersten Hälfte des Cinquecento vgl. insbes. Bölling 2006, S. 94-97 über die Regelungen bei Paris de Grassis.

313 Brev. Rom. (MLCT, 3), S. 493 innerhalb der Oktav und entsprechend in ibid., S. 495 an den Sonntagsfeierlichkeiten. 
Bezug auf die Kirchengeschichte eine neue Erzählform für die Darstellung der Romana Ecclesia, deren Entstehung und Entwicklung im Einklang mit den rituellen Vorschriften ihrer überlieferten Liturgie stand, erschlossen werden. Der Historia Ecclesiastica wurde dadurch ein Platz unter den heiligen Büchern zugewiesen.

Demzufolge stellte die Kirchengeschichte nicht nur eine Erzählung der Kirche ab der Menschwerdung Gottes dar. Neben den Glaubensinhalten hatte sie mittels ihrer Darstellung der Verbreitung des Evangeliums auf dem orbis Christianum auch die sich sichtbar im Vollzug des römischen Ritus offenbarende Liturgie auszulegen. In den Augen der römischen Kurie und insbesondere Sirletos bot die Kirchengeschichte ein geeignetes Instrument, mit welchem die zeremoniellen Gestaltungen spezifischer liturgischer officia rekonstruiert werden konnten. Die Kurie nahm sich somit eines Themenbereichs an, mit dessen Hilfe sie die Kontinuität zwischen apostolischen Zeiten und ihrer Gegenwart nachweisen wollte. Sirleto bot der Kurie mit seinen Arbeiten sowohl am Catechismus als auch am Breviarium und am Missale Romanum die entscheidenden Voraussetzungen, mit denen eine erfolgreiche Widerlegung der Zenturien angestrebt werden konnte. Der Jesuitenpater Petrus Canisius gilt als einer der ersten, die sich dieser liturgischen Voraussetzungen in Hinblick auf eine Widerlegung der Zenturiatoren bedienten. Canisius' Bemühungen, eine von der Kurie bestätigte Kirchengeschichte vorzulegen, zeigen aber, dass die ersten dieser Versuche erfolglos blieben, auch wenn innerhalb der Kurie ab 1565 eine Kardinalskommission gegen die Magdeburger Zenturiatoren arbeitete. Ein Schreiben des Jesuiten Juan Polanco an seinen Ordensbruder Alfonso Salmerón vom 16. September 1565 bestätigt das Bestehen einer solchen Kongregation, die sich mit einer Widerlegung der Zenturiatoren und ihrer Ecclesiastica Historia auseinandersetzte. ${ }^{314}$

Der bereits erwähnte Brief vom 17. September 1565, den Canisius an Stanislaus Hosius verfasste, erwähnt zudem, dass die Jesuiten - zumindest im ersten Jahr nach der Einberufung jener Kommission - einen grossen Teil der Mitglieder derselben ausmachten. Die ersten Tätigkeiten der Kommission verzögerten sich allerdings durch den Tod Pius' IV. einerseits und die Vorbereitungen zum bevorstehenden Augsburger Reichstag andererseits. Es ist jedoch klar, dass es vorerst der Jesuitenorden gewesen sein muss, der für eine Widerlegung der Zenturien beauftragt wurde. Die Kurie nahm nach dem Augsburger Reichstag von 1566 ihre eigenen Arbeiten an einer Widerlegung protestantischer Kirchengeschichtsschreibung entsprechend wieder auf. Der be-

314 MHSI, Epistolae Salmeronis, II, S. 31: „Qui va una lettera per detto Bernardo (Maizza). Si tratta delle centurie, dividendo la fatica fra molti; et la parte delli dogmi pare hanno dato al P. Ledesma." Ein weiterer Brief Polancos an den Jesuitenprovinzial in Sizilien, Hieronymus Domenech, vom 17. September desselben Jahres erläutert ebenfalls dieses Projekt und nennt Salmerón als eines ihrer Mitglieder. Das Schreiben befindet sich in ARSI, Epp. Ital. 1565-1567, f. 19r: „Volendo S. Santità se scriva un'opera contra quelle Centurie delli heretici che fanno tanto danno alla Religione Catholica, fra alcuni altri è stato eletto il Padre Salmeron, por parte del Papa“. Vgl. auch Miguel Medinas Beschreibung der Kongregation in ASV, Nunz. Spagn. 17, f. 45r-v. 
reits erwähnte Kardinal Marcantonio da Mula schlug Stanislaus Hosius ursprünglich vor, dass der Jesuit Francisco Torres eine solche kuriale Widerlegung der Zenturien strategisch ausarbeiten sollte. Ein von Petrus Canisius verfasster Memorialtraktat, den der päpstliche Legat Giulio Pavesi anlässlich seiner Reise in die Niederlande von Dillingen aus nach Rom senden wollte, präsentiert eine weit radikalere Strategie der Widerlegung der Magdeburger Zenturiatoren als diejenige, welche die Kurie im Sinne hatte. Canisius geht es nicht nur um eine allgemeingültige Widerlegung des Werkes. Seinen Vorstellungen zufolge müsste innerhalb der Kurie ein Arbeitskreis gegründet werden, der weitere Werke der Protestanten herabzusetzen im Stande wäre. Die Mitglieder dieses Arbeitskreises sollten sich des in der Biblioteca Vaticana überlieferten Handschriftenmaterials bedienen, um dadurch eine verlässliche Widerlegung häretischer Bücher aus dem Bereich der Kirchengeschichtsschreibung durchführen zu können. ${ }^{315}$ Am 31. Mai 1567 teilte der General Francisco Borja dem Jesuitenpater Canisius mit, dass er das päpstliche Mandat zur Widerlegung der Zenturien erhalten habe und nun Canisius selbst beauftrage, ein solches Buch gegen die Zenturiatoren zu verfassen:

Il modo di far questo libro, dice sarebbe questo, che li nostro che stanno in diverse bande in Germania, come sono li Dottori di Dilinga, Ingolstadio, Monachio, et altri di Colonia ò altri luoghi del Rheno et Infer Germania notassino quello che potessino à questo proposito et mandassino una silva à V.R. la quale poi del tutto potria ordinare un libretto [...]. ${ }^{316}$

Das Resultat der ersten Arbeiten des Jesuitenpaters in Dillingen stellt sein 1571 erschienener Commentariorum de Verbi Dei corruptelis dar. In diesem legt Canisius eine Widerlegung der Zenturien vor, die sich des im Johannes-Evangelium enthaltenen Verständnisses der Menschwerdung Gottes sowohl als logos als auch als verbum Dei bedient (Joh 1, 14). Mit diesem Kommentar beabsichtigte Canisius, die Zenturien damit zu widerlegen, indem er diese als eine theologische Darstellung des Verfalls der Kirche nach der Fleischwerdung Gottes auffasste. Sechs Jahre später legte Canisius einen weiteren Traktat vor, welcher der unbefleckten Empfängnis der Gottesmutter gewidmet war. Beide Abhandlungen wurden dann 1583 in einer überarbeiteten Fassung neu gedruckt. Das Werk über die göttliche Fleischwerdung

315 Die Kenntnis über ein solches Memorial des Dillinger Jesuiten Canisius kann aus einem Brief desselben Nadals an den Jesuitengeneral Borja vom 6. Juli 1566 rekonstruiert werden: MHSI, Epistolae Nadadal, IV, S. 215 sowie Orella y Unzue 1976, S. 193. Das memoriale findet sich auch abgedruckt in Braunsberger 1909, S. 62. Der Jesuit und im Arbeitskreis der Correctores Romani angehörige Torres, auch Turrianus genannt, wird aber erst in den späteren Arbeiten der Kongregation wieder auftauchen. Vgl. zu Torres DDC 1965, Bd. 7, Sp. 1352.

316 Braunsberger, Canisius Epistulae et acta, V, S. 480. Bis zu diesem Auftrag versuchte Canisius aber den Augustinermönchen Panvinio für die römischen Arbeiten gegen die Zenturien zu gewinnen. Am 29. September 1567 teilte ihm nämlich Canisius mit, dass mit dem Kölner Druck seines Chronicon Ecclesiarum und seiner drei Bücher gegen die Historiam Magdeburgicam begonnen wurde. Ebenfalls war Canisius bereit, Panvinio den zehnten sowie den elften Band der Zenturien nach Rom zu schicken. Vgl. hierzu das Briefschreiben in Braunsberger, Canisius Epistulae et acta, VI, S. 72. 
im Johannes-Evangelium ist in mehrere Kapitel gegleidert, mit denen Canisius auf ausgewählte Stelle in den Magdeburger Zenturien verweist und diese widerlegt. Der Jesuit Alfonso Salmerón gratulierte Canisius 1572 zum Abschluss seines ersten Werkes und lobte es. Es biete ,in einzigartiger und wundersamer Art Frömmigkeit, tiefe Gelehrsamkeit, eine sorgfältige Lesart der Kirchenväter, die bemerkenswerte Begegnung mit den Häretikern und eine authentische und orthodoxe Auslegung des Gotteswortes“. 317 In der praemonitio seines Kommentars erläuterte Canisius den hauptsächlichen Grund, weshalb der Gebrauch der Fleischwerdung Gottes über die Jahrhunderte verfallen ist. Für den Jesuitenpater stellen die Magdeburger Zenturien eine Synagoge Satans dar, mit welcher die protestantischen Theologen das fleischgewordene Gotteswort verschmutzen würden. ${ }^{318}$ In einer weiteren Passage erklärt Canisius, dass Luthers Taten „diesen gegenwärtigen Satanismus vor fünfzig Jahren einführten, um die Kirche zu spalten und Staatsgewalten zu destabilisieren”. ${ }^{319}$ In der Tat war es Canisius‘ Ziel, wie Salmerón ebenfalls beobachtete, ,vielmehr den Leser zu unterrichten als ihn zu unterwerfen“ und somit „die Wunden zu heilen als neue zu öffnen“. 320

Den ersten Teil seiner Widerlegungen der Zenturien hatte Canisius gemäss seiner eigenen Überzeugung, dass eine korrekte Kirchengeschichte aus der christlichen Lehre - aus dem Catechismus also - abgeleitet werden sollte, verfasst. Canisius löste damit aber nur einen Teil seines Versprechens gegenüber der Kurie ein, da diese erste Arbeit weit von einer historiographischen Abhandlung entfernt war. Die Widerlegungen des Jesuitenpaters zeigten aber noch lange nicht, wie sich eine Historia Evangelica in eine Historia Ecclesiastica umwandeln liess, auch wenn Canisius in seinem Werk diesen Übergang stets angestrebt hatte. ${ }^{321}$ Allerdings nahm die theologisch tiefgründige Arbeit an einer Verteidigung der Apostel und der Jungfrau eine beträchtlicheZeit in Anspruch. Dies war aber nicht der alleinige Grund, weshalb sich die Arbeiten des Jesuitenpaters als ineffizient entpuppten und damit scheiterten. Die Kurie

317 Braunsberger, Canisius Epistulae et acta, VII, S. 40-41. Selbst Stanislaus Hosius lobte das Werk in einem Briefschreiben an Papst Pius V. vom 8. Juni 1571, als der Ermländer Erzbischof sich in Subiaco ausruhte: ibid., VI, S. 710. Hosius führte auch Sirleto unter denjenigen Prälaten auf, die Canisius‘ Kommentar bereits gelesen hatten.

318 Canisius, Commentarium de verborum Dei, c. b4v, c1r.

319 Ibid., c. 180r: „[...] cum eius opera sit illud effectum, ut presens hic Sathanismus, quem ex omnium fere hereson colluvie concretum esse cernimus, his annis quinquaginta fuerit introductus, et in tota fere Europa vires ad scindendam Ecclesiam, \& ad imperia disturbanda [...]“.

320 Braunsberger, Canisius Epistulae et acta, VII, S. 41: „[...] plane ut docere magis praeteferas, quam revincere, sanareque potius, quam vulnera refricare videaris“.

321 Braunsberger, Canisius Epistulae et acta, VI, S. 419: „Non solum adversus Centuriatores sed alios Novatores bellum ingens hoc in opere suscepi, ut plenior saepe et necessaria sit confutatio. Spero Dei bonitate et favente P. T. fore ut sequenti aestate labor hic omnis exitum consequatur, absolutis nimirum his, quae sunt prae manibus, modo de praecipuis illis personis et Sanctis novi Testamenti Joanne, Maria et Petro in quibus ornandis, et adversus haereticos defendendis cupio laborem plus quam vulgarem meum exstare, alij de alijs et melius et uberius tractent“. Vgl. dazu auch ibid., S. 435-439, insbes. S. 436-437; Benz 2003, S. 29. 
erhob nämlich mit Hilfe der Arbeiten Sirletos am Breviarium und Missale Romanum den Anspruch, die liturgisch-zeremonielle Form des römischen Ritus zu historisieren und damit eine kirchenhistoriographische Entstehung sowie Entwicklung der römischen Liturgie präsentieren zu können.

In dem 1568 erschienenen Brevirarium Romanum hatte sich erstmals dieses Bedürfnis nach einer kirchenhistorischen Erzählung manifestiert, mit welcher die römische Liturgie historisiert werden konnte. Es ist daher kein Zufall, dass sich Petrus Canisius im ersten Teil seiner Arbeiten gegen die Magdeburger Zenturiatoren auf die Apostelfigur Johannes des Täufers bezog. Denn in der fünften lectio zum Fest des Apostels wird eine Lebenserzählung von den Verfolgungen Kaiser Neros bis zur Kaiserzeit Trajans geboten. ${ }^{322}$ Von einer solchen Historisierung des Apostels Johannes ist im Kommentar des Jesuitenpaters von 1571 aber keine Spur zu finden. Dieser Umstand lässt sich nur dadurch erklären, dass Sirletos Arbeiten am neuen Breviarium und am neuen Missale Romanum innerhalb der römischen Kurie eine noch von den Kongregationsarbeiten gegen die Magdeburger Zenturien unabhängige Auseinandersetzung mit der kirchenhistoriographischen Bedeutung der Evangelisten verfolgen konnten. Die seit 1565 ins Leben gerufene Kommission gegen die ZenTturiatoren und diejenige zur Revision der liturgischen Bücher gemäss den Tridentiner Beschlüssen arbeiteten in einer Parallelkonstellation, ohne einen wirklichen Austausch zu pflegen. Diese unabhängige Arbeitsweise der Kommissionsmitglieder zeigt, dass die Jesuiten mit Petrus Canisius der Meinung waren, dass am Anfang einer Widerlegung der Zenturien die Apostel aus der Heiligen Schrift neu aufgearbeitet werden mussten. Auch wenn sie wegen dieser zeitaufwendigen Arbeitsweise scheiterten, konnten die Jesuiten nichtsdestotrotz ihre Widerlegungsstrategie gegenüber den Forderungen der Indexkongregation aufrechterhalten. Ein anderer Fall zeigt jedoch, wie der Versuch der Vereinheitlichung einer liturgischen Aufarbeitung des römischen Ritus und der Historisierung sowohl der Romana Ecclesia als auch des Papsttums zwangsläufig scheitern musste.

322 Brev. Rom. (MLCT, 3), S. 194. Einen entscheidenden Beitrag hierzu leistete eine in BAV, Vat. lat. 6171, f. 126r-127r anonym gebliebene Ausführung darüber, zu welchem Zeitpunkt der Apostel Johannes sein Evangelium niederschrieb. Diese Ausführungen sind ebenfalls Sirleto zuzuschreiben. 